Portland State University

PDXScholar

Dissertations and Theses

Dissertations and Theses

Summer 8-29-2013

\title{
A New Low in Getting High: Illegal Drug Use and Crime
}

Erica Jean Ferrelli

Portland State University

Follow this and additional works at: https://pdxscholar.library.pdx.edu/open_access_etds

Part of the Criminology and Criminal Justice Commons, and the Family, Life Course, and Society Commons

Let us know how access to this document benefits you.

\section{Recommended Citation}

Ferrelli, Erica Jean, "A New Low in Getting High: Illegal Drug Use and Crime" (2013). Dissertations and Theses. Paper 1123.

https://doi.org/10.15760/etd.1123

This Thesis is brought to you for free and open access. It has been accepted for inclusion in Dissertations and Theses by an authorized administrator of PDXScholar. Please contact us if we can make this document more accessible: pdxscholar@pdx.edu. 
A New Low in Getting High: Illegal Drug Use and Crime

by

Erica Ferrelli

A thesis submitted in partial fulfillment of the requirements for the degree of

Master of Science

in

Sociology

Thesis Committee:

Melissa Thompson, Chair

Randy Blazak

Lindsey Wilkinson

Portland State University

2013 


\begin{abstract}
The current research analyzed the relationship between methamphetamine use, cocaine use and marijuana use within the last 12 months and crime committed within the last 12 months. Crime is defined as drug sales, property and violent crime. The research design is a quantitative approach which uses secondary data analysis of the National Longitudinal Survey of Adolescent Health (Add Health) to provide evidence toward the research question; does illegal drug use increase the risk of committing a crime?

The public access, 2008 Wave III data results of this nationally representative sample of adolescents in grades 7 through 12 in the US in the 1994-95 school year was used for analysis. Methamphetamine use was associated with an increased risk of committing all crime, only until cocaine use was controlled for. Once cocaine use was controlled for, methamphetamine use became non-significant. Cocaine use and marijuana use were significant and associated with an increased use of committing a crime.
\end{abstract}


Table of Contents

Abstract.......................................................................

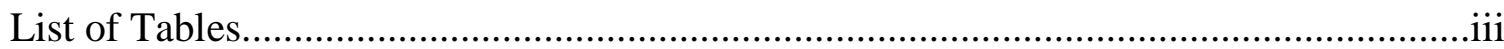

\section{Chapter 1}

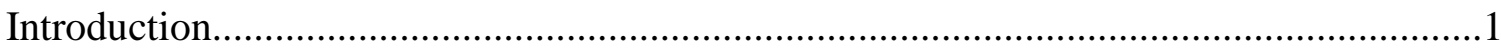

Chapter 2

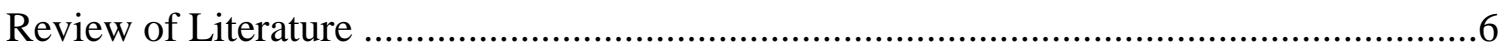

Chapter 3

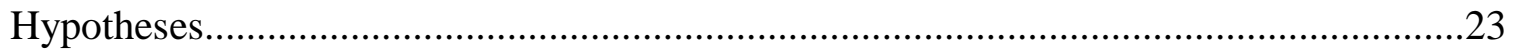

Chapter 4

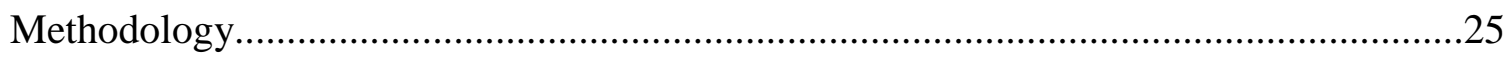

Chapter 5

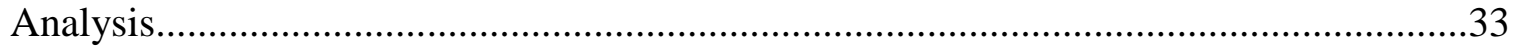

Chapter 6

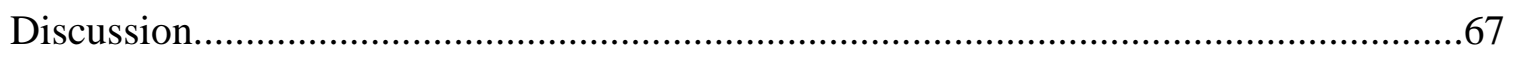

\section{Chapter 7}

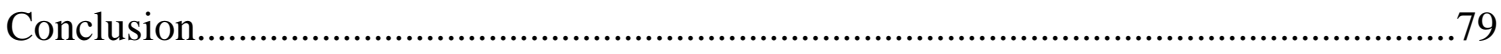

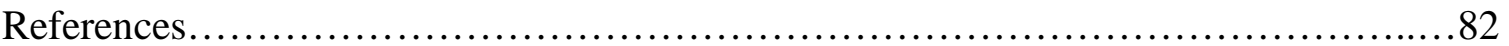




\section{List of Tables}

Table 1: Univariate Analysis............................................ 33

Table 2: Demographics of Methamphetamine Users within the past 12 months .........38

Table 3: Cross Tab of Illegal Drug Usage (past $12 \mathrm{mths}$ ) and Its Impact on Drug Sales

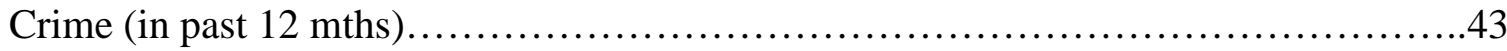

Table 4: Cross Tab Illegal Drug Usage (past $12 \mathrm{mths}$ ) and Its Impact on Property Crime

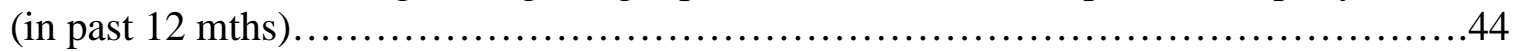

Table 5: Cross Tab Illegal Drug Usage (past $12 \mathrm{mths}$ ) and Its Impact on Violent Crime

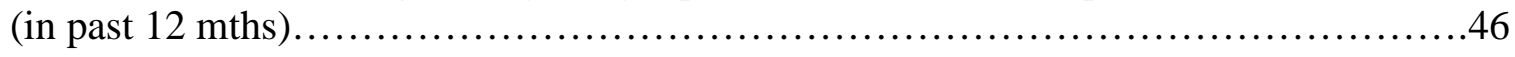

Table 6: Logistic Regression of Drug Sales...................................47

Table 7: Logistic Regression of Property Crime...............................54

Table 8: Logistic Regression of Violent Crime...............................60 


\section{Chapter 1. Introduction}

"As the national outcry and panic over the crack epidemic abates, public attention and concern is now concentrated on a supposed worse drug: methamphetamine" (Sommers \& Baskin, 2006, p. 77). Methamphetamine is a derivative of amphetamine, also called meth, crystal, or speed. It is a central nervous system stimulant that can be injected, smoked, snorted, or ingested orally. Methamphetamine is manufactured easily in covert laboratories with inexpensive and easily obtainable ingredients. The factors of easy manufacturing and a high rate for dependency combine to make methamphetamine a drug with a high potential for widespread use and abuse. Our country has a long history of demonizing certain drugs during certain time periods and scapegoating the drug for the nation's problems. Methamphetamine seems to have taken the place of the once feared and demonized drug crack/cocaine. Reinarman (1994) states, that crack became scapegoat for the nation's poverty crime and moral degeneracy, unemployment and personal and business failure"(p. 157). As with the crack epidemic, sensationalized headlines have become common in newspapers, television reports and billboards across the country, leaving many Americans with an obscured view of methamphetamine use and its effects.

Media reports around the United States have virtually created the idea that methamphetamine abuse has reached rampant proportions (King, 2006). According to Chitwood et al. (2009) these reports often include depictions of a scourge raging across the country and enveloping communities in chaos. The media in turn feeds this sense of alarm that it has created by continuously "circulating the dire reports delivered by 
officials from the reported epicenters of use" (Chitwood et al., 2009, p. 32).The spirit of these images is reflected in newspaper headlines like these: "Spread of meth near epidemic, Czar says" (Ruff, 1997); "Governor warns meth epidemic growing like kudzu" (Bluestein, 2004); "Officials brace for meth epidemic; labs on the rise in New England" (Valencia, 2005); “Attorney General calls meth an epidemic in Illinois” (Nauman, 2005); and "Meth epidemic forcing grandparents to raise grandchildren" (Dillon, 2006).The parallels between the coverage of crack in the 1980s, where it was described as a "plague" and an "epidemic," and the reporting on methamphetamine are so striking one could swap the word "meth" for "crack." And some stories seem to have done exactly that: "Methamphetamine sinks its teeth into Arkansas; like crack's epidemic rise in '80s, police say" (Waite, 1999).

By simply replacing the word crack with meth the media has created this similarity in effect between the two drugs. Therefore, whatever adjective, crime or behavior was associated with crack/cocaine use in the 1980's is now associated with methamphetamine use during this new epidemic time. However, research studies are conflicting as to whether methamphetamine and cocaine are as similar in effect as the media portrays them. Some literature shows a similarity between cocaine and methamphetamine and the effects that each drug has on its users. Methamphetamine and cocaine are both powerful psyihostimulants hat produce very significant acute and chronic effects and serious negative consequences in the users' life (Rawson et al., 2000).

"Amphetamines cause a number of effects that are sought by the abuser, for example, a sense of increased energy, self-confidence, and well-being; heightened awareness; loss of appetite; and euphoria. In addition to these effects, the drugs 
cause bronchodilation and an increase in heart rate and blood pressure. In previous years, amphetamine abusers have included occasional users who wanted to stay awake, obese persons who wanted to lose weight, and compulsive users. This is comparable to the effects cocaine use has on its user "(Beebe \& Walley, 1995, p. 449).

Users of cocaine describe the effects of the drug similarly. This description includes feelings of euphoria, increased energy, talkative, and mentally alert. It can also temporarily decrease the need for food and sleep (Siegel, 1984). Cocaine use has repeatedly been associated with an increased risk of committing a crime once a user has taken the drug. Therefore, it becomes imperative to research whether or not the similarities of cocaine and methamphetamine transcend into whether using methamphetamine also increases the risk of the user to commit a crime.

The differences in the effects of cocaine and methamphetamine use are firstly, the way in which the body mechanisms respond to the drug once it has entered the body.

"Although their overall actions are similar, there is a fundamental difference in the mechanisms by which amphetamine and cocaine increase neurotransmitter levels in the synaptic cleft. Cocaine appears to inhibit the removal of transmitter that is released by neuronal activity and its action is dependent on extracellular, whereas amphetamine causes transmitter to be transported extraneuronally (Beebe \& Walley, 1995, p. 449).

Secondly, there are psychopharmacological differences between crack and methamphetamine use. In contrast to crack/cocaine, methamphetamine produces a more powerful and longer lasting high. It is imperative to study whether or not these differing effects transcend into the risk of committing a crime once a user has taken the drug.

Almost every state legislature in the USA has recently enacted laws to prevent methamphetamine manufacture and use while continued high salience of the "negative 
effects' of methamphetamine use flood the popular press (Zernike, 2006). New, harsher laws were also passed during the crack/cocaine epidemic in an attempt to get tough on drugs and control the outbreak of use and portrayed destruction of this 'new demonized drug'. However according to Reinarman (1994), new laws and harsher penalties for crack/cocaine use did not arise when the prevalence of cocaine use quadrupled in the late 1970's nor even when thousands of users began to smoke it in the more potent and dangerous form of freebasing. Rather this drug scare was launched in 1986 when freebase cocaine was renamed crack and sold in pre-cooked, inexpensive units on the ghetto street corners. "Once politicians and the media linked this new form of cocaine use to the innercity, minority poor, a new drug scare was underway and the solution became more prison cells rather than more treatment slots" (Reinarman,1994, p. 159). These new laws were enacted without any study documenting an actual associated risk between crack cocaine and any of the destructive societal effects this drug was said to have on the user. Drug use becomes a problem when it is said to be affecting society negatively, either by the media or politicians. Therefore, one of the negative effects that most Americans fear especially by those individuals who have ingested these 'demonized' substances is crimes committed to them. Crime affects society as a whole and is used by not only the media but politicians to fuel the fear fire in Americans. Therefore, if politicians and the media claim that drugs use is associated with an increased risk of committing crime more Americans might be tempted to vote or be in favor of harsher laws that would keep these drug users behind bars. This strategy was used by politicians and the media during the crack/cocaine epidemic. This strategy ended with crack/cocaine users, who were mostly 
African American and of low income, serving a sentence more than 8 times longer than their white middle class powder cocaine user (Angeli, 1996).

The enactment of harsher penalties for crack distribution, manufacturing and possession did not lead to decrease in crime committed by the user. Cocaine use has been shown in previous research to be significantly associated with crime (McGlothlin, 1978; Anglin \& Speckart, 1988; Beebe \& Walley, 1995; Lattimore, 1997; Rawson et al., 2000; Garlow et al., 2002; Glasner-Edwards, 2008; Chitwood et al., 2009). Also, our society cannot afford to imprison even more people than we already have locked away now. Therefore, since the imprisonment of crack users did not prevent the user or deter other users from committing crime and society cannot afford another mass imprisonment, in particular, those of low economic and minority standing, it is essential to first provide evidence toward the basic research question, 'does methamphetamine use increase the risk of committing crime? Although national surveys indicate that the prevalence of methamphetamine use is highest among young adults (SAMSHA, 2005), few research studies based on nationally representative data have examined the association between methamphetamine use, cocaine use, marijuana use and crime within this age group. This thesis is based on data from The National Longitudinal Study of Adolescent Health (Add Health) 2008, which asked respondents about their use of methamphetamine, cocaine and marijuana in the past year and past 12 months. Add Health's nationally representative sample of young adults was used to examine the association between illegal drug use and crime. 


\section{Chapter 2. Literature Review}

\section{History of Methamphetamine}

Methamphetamine (MA) is a derivative of amphetamine and was first synthesized from ephedrine in 1893 by Japanese pharmacologist A. Ogata (Suwaki, Fukui \& Konuma 1997). It wasn't until World War II when Japan, Germany, and the United States provided the drug to military personnel to increase endurance and performance that methamphetamine started to become widely used. Beginning in 1941, MA was sold in Japan over the counter as Philopon and Sedrin, advertised as a product to "fight sleepiness and enhance vitality." Therefore, the drug was promoted to aid increased productivity of civilian factory workers in military support industries. Widespread abuse only occurred after the war ended (Anglin et al., 2000). Methamphetamine from surplus army stocks flooded the market, leading to the "First Epidemic" (1945-1957). "By 1948, Methamphetamine had suggestively been abused by about $5 \%$ of Japanese people age 16 to $25 "$ (Anglin et al., 2000, p. 138).

In the United States, amphetamine was also used in the treatment of certain medical conditions. "Amphetamine tablets were available without prescription until 1951 and amphetamine-containing inhalers were available over the counter until 1959. During the 1960s, amphetamine was widely prescribed and used to treat depression and obesity" (Anglin et al., 2000). Additionally, in the 1960's a liquid form of methamphetamine began gaining popularity by the medical community and was used as a treatment for heroin addiction (Anglin et al., 2000). “The black market in amphetamine consisted 
mainly of illegally diverted supplies from pharmaceutical companies, distributors, and physicians" (Anglin et al., 2000, p. 139 ). It wasn't until after the withdrawal of Desoxyn and Methedrine from the pharmaceutical market, those illicit methamphetamine laboratories began to emerge in San Francisco in 1962.

As the 1970s approached, research was being conducted on the effects of methamphetamine which led to additional restrictions being placed on the amount that could be legally produced and thus how and to whom it could be distributed (Anglin et al., 2000). With these new restrictions in place increased levels of illicit production ensued. Illegal production at this point in time was limited to motorcycle gangs and a very small amount of independent manufacturers (Lucas 1997). Additionally, as the 1970's progressed, the typical user population changed from white, blue-collar workers to include college students, young professionals, minorities, and women (Potter \& Kolbye, 1996).

By the 1980s, law enforcement efforts targeting the biker groups had intensified coupled with a simpler, ephedrine reduction-based method of production. This caused production and distribution, to shift to the San Diego area which added a greater involvement of Mexican traffickers (Morgan \& Beck, 1997). "Large quantities of illicitly produced ‘crystal meth’ were smuggled from Mexico into California and were distributed not only in the traditional regions of use but also were increasingly directed toward the southwestern and mid-western states" (Anglin et al., 2000). During the 1990s, the use of "ice" was rampant in the Hawaiian Islands. Distribution of the drug was gradually 
dominated by Mexico and California based trafficking organizations (Laidler \& Morgan 1997).

Clandestine labs operating in California and Mexico are still the primary sources of methamphetamine available in the United States. However, a growing number of MA labs are operating in midwestern states (Office of National Drug Control Policy 1997). In response to the growing public health threat posed by the use and production of methamphetamine (and especially environmental hazards associated with the toxic compounds used in the clandestine labs), the Comprehensive Methamphetamine Control Act was enacted in 1996. The MCA broadens controls on listed chemicals used in the production of methamphetamine, increases penalties for the trafficking and manufacture of methamphetamine and listed chemicals, and expands controls to include the distribution of lawfully marketed drug products which contain the listed chemicals ephedrine, pseudoephedrine and phenyl-propanolamine (PPA) (Anglin et al., 2000).

\section{Increasing Use of Methamphetamine}

Methamphetamine use is increasing in the United States according to the national Survey on Drug Use and Health 2009. This increase in use is shown by a variety of indicators. In 2004, an estimated 12 million persons (4.9 of the general population aged twelve and older) had used methamphetamine at least once in their lifetime (Substance Abuse and Mental Health Services Administration 2005). Methamphetamine use declined drastically and by 2008 , only $5 \%$ of the population had used methamphetamine in their lifetime (Substance Abuse and Mental Health Services Administration 2008). However, 
methamphetamine use has increased slightly and has stayed consistent from 2009 until 2011 at $5.1 \%$ of the population having tried methamphetamine sometime in their lifetime (Substance Abuse and Mental Health Services Administration 2008).

Another indicator of an increase in the use of methamphetamine is an increase in treatment admissions due to methamphetamine use. Treatment admissions of persons with methamphetamine use problems increased from 21,000 in 1993 to 117,000 in 2003 (Sommers \& Sommers, 2006). Specifically, the west coast has seen a vast increase in admissions to publically funded treatment facilities by methamphetamine users. According to Brecht (2001), admissions to publically funded treatment facilities in California by methamphetamine addicts increased 226 percent from 1992 to 1998. Additionally, emergency department records and medical examiner reports involving those patients who were involved with methamphetamine use doubled as the new millennium approached (Substance Abuse and mental Health Services Administration, 2003). Also, recent trends suggest that methamphetamine's popularity has grown among college students, and methamphetamine is now included in this group's repertoire of "party drugs" (Somers \& Baskin, 2006). However, little research has been conducted using a nationally representative survey on young adults and methamphetamine use.

The possible increasing trends in methamphetamine use are of major concern because of the destructive, harmful, and deadly effects that methamphetamine use can cause. Chronic methamphetamine use can cause violent behavior, anxiety, confusion and insomnia. Additionally, some users exhibit psychotic behavior, mood disturbances, delusions and paranoia (Albertson, Walby, \& Derlet, 1995). However, even when one 
attempts to discontinue methamphetamine use, withdrawal symptoms usually occur and can be just as detrimental as or even more dangerous than the effects of actual drug use. These withdrawal symptoms include depression, anxiety, fear, fatigue, paranoia and intense cravings for the drug (Katsumata, Sato, \& Kashiwafe, 1993).

\section{Effects of Methamphetamine}

"Crystal", "meth," or "speed," as MA is variously called, can be injected, smoked, snorted, or ingested orally. The timing and intensity of the "rush" that accompanies the use of MA, which is a result of the release of high levels of dopamine into the brain, depend in part on the method of administration. The effects are almost instantaneous when MA is smoked or injected; they occur approximately five minutes after snorting or 20 minutes after oral ingestion. Immediate physiological changes associated with the use of MA are similar to those produced by the fight-or-flight response and include increased blood pressure, body temperature, heart rate, and breathing rate. Negative side effects include high body temperature, stroke, cardiac arrhythmia, stomach cramps, and shaking, as well as increased anxiety, insomnia, aggressive tendencies, paranoia, and hallucinations.

Prolonged use of MA may result in a tolerance for the drug and increased use at higher dosage levels, creating a pernicious dependence. Such continual use of the drug, with little or no sleep, leads to an extremely irritable and paranoid state (National Institute on Drug Abuse 1998a). Discontinuing use of MA often results in a state of extreme depression, as well as fatigue, anergia, and cognitive impairment that lasts 
anywhere from two days to two weeks (National Institute on Drug Abuse 1998b).

Negative consequences of MA abuse range from anxiety and insomnia to convulsions, paranoia, and brain damage, but in addition to the many direct effects on MA users there are indirect impacts on individuals and society.

\section{Theory of Drug Use, Crime and Violence}

Goldstein (1985) explains the drug crime nexus as a three modeled approach. This model postulates that the connection between drugs and violence can be found through the application of one or more of three models; Systematic, Economic and/or Pharmacological. The first model is systematic. The systematic model suggests that those involved with the illegal drug market, such as distributing or manufacturing illegal drugs have an increased association with crime and violence. Blumstein (1995) argued that drug market norms are especially important when considering levels of crime and violence. Rival drug dealers cannot call upon the police to protect them when they feel threatened because of their involvement in illegal activity. Therefore, rival drug dealers will take care of the problem themselves, usually with deadly force (Blumstein, 1995). Researchers such as Blumstein argue that the increase in the homicide rate observed in several cities in the 1980s is associated with the emergence of crack cocaine markets and the resulting recruitment of young gang members into that drug network. However, with the methamphetamine market there is little evidence suggesting that it has a market structure similar to that of crack cocaine. In essence, the affiliation that most crack/cocaine dealers have with gang activity is what accounts for a majority of the violent and property crime committed by these dealers. Methamphetamine dealers are 
small time entrepreneurs who are selling to a small net of people, the criminal and violent activities that accompany cocaine dealers should not accompany methamphetamine dealers. If a relationship between methamphetamine and crime does exist, the literature on drug use does not appear to suggest that the relationship is likely to be systemic in nature (Sommer \& Baskin, 2006).

Second, Goldstein (1985) defines economic-compulsive crime as the efforts drug users use to obtain money to finance the high costs of illicit drugs. This could be robbery, burglary or larceny in which the money is used to finance the drug habit. Violent criminal activity could occur if the individual uses physical force or the threat of physical force in order to obtain finances to support their drug habit. In the case of methamphetamine, it has been suggested that however, economic-compulsive violence is less likely than for other drugs. For example, some drug habits such as cocaine and heroin are expensive and so economic violence is more likely to be related to these particular drugs (Boles \& Miotto, 2003). Additionally, methamphetamine is more likely than other drugs such as crack cocaine to be made for consumption purposes by small-time entrepreneurs (Wermuth, 2000). Therefore, methamphetamine users are purchasing cheaper drugs and are purchasing their drug of choice from a small time entrepreneur instead of a gang, cartel or larger scale drug trafficking organization which may imply a weaker link between methamphetamine and economic-compulsive crime.

Third, the reason for the potential association between methamphetamine crime and violence may also be pharmacological (Fischman \& Haney, 1999). That is, methamphetamine changes the body's chemistry in a way that makes users act violently 
(Kosten \& Singha, 1999). Medical researchers, for instance, have argued that methamphetamine is a neurotoxin that acts on the central nervous system to produce a variety of physical manifestations and psychiatric complaints such as "depression with severe dysphoria, irritability and melancholia, anxiety, marked fatigue with hypersomnia, intense craving for the drug, and even paranoia or aggression" (Meredith et al., 2005, p. 143). Methamphetamine may lead to more violence by increasing the stakes in everyday social interactions and "transforming them from non-challenging verbal interactions into the types of character contests whose resolution often involved violence" (Sommers \& Baskin, 2006, p. 92). Additionally, it has been suggested that potential biological effects of methamphetamine may be intensified by situational circumstances. In a review of the drug violence relationship literature, Parker and Auerhahn (1998) noted that a lack of social interaction may increase the chances for amphetamine-related violence because users are unable to "cross-check" their behavior.

\section{Methamphetamine Use and Violent Crime}

Numerous studies have reported associations between substance use and violent behavior. Some studies have examined methamphetamine use among subgroups, which include the homeless, runaways and street youth (Gleghorn, Marx, Vittinghoff \& Katz, 1998), while others strictly have dealt with those removed from society, such as juvenile arrestees and those in treatment (Pennel et al., 1999; Rawson et al., 2005), but none have shown the effects of methamphetamine use in comparison to those who have not used methamphetamine. Additionally, in most studies involving illegal drugs use, all illegal drugs tend to be grouped together, and there is no distinction made between whether a 
certain drug leads to a higher risk of violent behavior while another has no relationship Few studies have made the distinction between methamphetamine and its association with violence in comparison to others drugs. The few studies that have made this distinction and focused solely on methamphetamine use have conducted their studies on adult, self -selected chronic methamphetamine users and violence (Sommers \& Baskin, 2006, Cartier, Farabee \& Prendergast, 2005, Gizzi \& Gerkin, 2009). These chronic users are selected based on their enrollment in a treatment program, an admission to a hospital because of a methamphetamine related health problem or arrested and selected based on test records that indicate methamphetamine was in their system at the time of arrest. Although previous research studies have hypothesized that a causal relationship exists between methamphetamine use and violence, the findings are ambiguous in demonstrating a significant association between the two.

Pennel et al. (1999) conducted a study of methamphetamine use in five western cities and found that one third of arrestees using methamphetamine cited violent behavior as a consequence of their use. Additionally, another study conducted in California using data from state prison parolees found that methamphetamine use was significantly predictive of self- reported violent criminal behavior (Cartier, Farabee \& Prendergast, 2005). Also, drug abuse has been found to be a factor in homicide (Baskin \& Somers 1998) and violence among adolescents (Bourgois, 1995). Sommers and Baskin (2006) studied 205 frequent methamphetamine users who resided in Los Angeles, California. Approximately one quarter (26.8\%) of the study respondents said that they were violent (defined as "any form of deliberate physical harm inflicted on another individual") while 
under the influence of methamphetamine, specifically in domestic violence at home, work, or social events (Sommers \& Baskin, 2006, p. 83).

Also, Cartier et al. (2006) examined the relationship between methamphetamine and violent crime (murder, manslaughter, robbery, and assault) among a sample of adult male parolees during the 12-month period following release from a California prison. The researchers studied 404 pairs of inmates that were matched on "age, ethnicity, sex offender status and commitment offense" (Cartier et al., 2006, p. 437). With the presumed association between methamphetamine and violent crime, the researchers discovered that those individuals who used methamphetamine were more likely than those who did not use methamphetamine to be returned to custody. Additionally, methamphetamine users were more likely to self-report that they acted violently than those who did not use methamphetamine. This finding could be attributed to the criminal justice system and the harsh effect prison has on an individual. Therefore, it could be the time served in prison that was truly responsible for the increased violence and not necessarily the methamphetamine use.

However, in another study, participants were selected from five local jails in western Colorado, with one additional sample from community correction clients in Mesa County, Colorado. Based on their methamphetamine use (or lack thereof), the arrestees were grouped into three categories. The first being regular meth users, those who said meth was their drug of choice or used meth most often. The second group was lifetime meth users, those who admitted to only trying meth. The third group is those who had 
never used methamphetamine. The results showed that methamphetamine use of any kind was not associated with violent criminal behavior (Gizzi \& Gerkin, 2009).

Also, Iritani, Hallfors, and Bauer (2007) also examined the relationship between methamphetamine use and criminal behavior among a nationally representative sample of 18- to 24-year-olds. The researchers found that although methamphetamine use was correlated with self-reported drug sales (i.e., potential drug market effects), it was not significantly correlated with self-reported violent behavior.

Although findings are mixed, clinical studies indicate that amphetamines, such as methamphetamine, may increase the likelihood of attack behaviors and aggression in humans (Pihl \& Hoaken, 1997; Reiss \& Roth, 1993). Additionally, non-clinical studies have suggested that methamphetamine use at high levels can result in methamphetamine induced psychosis, often associated with violent behavior. Therefore, chronic users' irritability and paranoia caused by methamphetamine use may initiate a violent reaction when brought into contact with others (Dillon, Fritz, Blanton et al., 2000).

\section{Methamphetamine Use and Property Crime}

Research has consistently demonstrated a high degree of correlation between drug use and economic criminal behavior (Nurco et al., 1989; NASADAD, 1990). Regarding property crimes, the correlation between drug use and crime could be explained by the economic motivation due to the high cost of illicit drugs. Sommers and Baskin (2006), state that methamphetamine is too cheap and easily accessible for individuals to steal in 
order to fund their drug habit and therefore, the crime that is committed by methamphetamine users would not be property related.

Gizzi and Gerkin (2009), however show the second largest category of arrest responses of methamphetamine users was property crimes. Property crimes were reported by $32.7 \%$ of regular meth users, $15.6 \%$ of lifetime meth users, and by 1 non-meth drug user. Of the 16 property crimes described by regular meth users, 11 could be characterized as fitting under the economic-compulsive model of the Goldstein framework. In each instance, the participant described the crime as being committed solely to finance his or her drug habit. Overall, $28 \%$ of the offenses described by regular meth users could be described as economic-compulsive crimes.

\section{Methamphetamine use and Drug Sales}

The crime of selling drugs is the primary criminal activity among drug users (Harrison \& Gfroerer, 1992). Gizz and Gerkin (2009), show that regular meth users were most likely to have their charges involve drug offenses. Drug possession and distribution charges represented $48.9 \%$ of all responses. Of the 43 drug charge responses, $28(65.2 \%)$ were possession charges.

Brecht et al. (2004) found that fifty-six percent of the respondents reported having sold methamphetamine. Thirty-seven percent of those who sold did so within 1 month of starting use. The average time selling was around 4 years. Even though it was suggested that methamphetamine dealers are more small time and sell to closer knit of people, forty-two percent of methamphetamine dealers reported carrying a weapon while dealing. 


\section{Methamphetamine/Cocaine Paradigm}

Literature is contradicting as to whether or not methamphetamine and cocaine are truly as similar as the media depicts them to be. Media reports around the United States have virtually created the idea that methamphetamine abuse has reached rampant proportions (King, 2006). According to Chitwood et al., these reports often include depictions of a scourge raging across the country and enveloping communities in chaos (2009). The media in turn feeds this sense of alarm that it has created by continuously "circulating the dire reports delivered by officials from the reported epicenters of use" (Chitwood et al., 2009 p. 32)The spirit of these images is reflected in newspaper headlines like these: "Spread of meth near epidemic, Czar says" (Ruff, 1997); "Governor warns meth epidemic growing like kudzu” (Bluestein, 2004); “Officials brace for meth epidemic; labs on the rise in New England" (Valencia, 2005); "Attorney General calls meth an epidemic in Illinois" (Nauman, 2005); and "Meth epidemic forcing grandparents to raise grandchildren" (Dillon, 2006). The parallels between the coverage of crack in the 1980s, where it was described as a "plague" and an "epidemic," and the reporting on methamphetamine are so striking one could swap the word "meth" for "crack." And some stories seem to have done exactly that: "Methamphetamine sinks its teeth into Arkansas; like crack’s epidemic rise in ‘80s, police say” (Waite, 1999).

The comparison between the effects of cocaine use and methamphetamine use has been documented in previous studies. (Garlow et al., 2002; Glasner-Edwards, 2008; Chitwood et al., 2009). However, the studies are lacking and the literature is contradictory as to whether or not methamphetamine and cocaine are truly as similar as 
the media depicts them to be. Some literature shows a similarity between cocaine and methamphetamine and the effects that each drug has on its users. Methamphetamine and cocaine are both powerful psyihostimulants hat produce very significant acute and chronic effects and serious negative consequences in the users' life (Rawson et al., 2000).

"Amphetamines cause a number of effects that are sought by the abuser, for example, a sense of increased energy, self-confidence, and well-being; heightened awareness; loss of appetite; and euphoria. In addition to these effects, the drugs cause bronchodilation and an increase in heart rate and blood pressure. In previous years, amphetamine abusers have included occasional users who wanted to stay awake, obese persons who wanted to lose weight, and compulsive users. This is comparable to the effects cocaine use has on its user "(Beebe \& Walley, 1995 p. 449).

Users of cocaine describe the effects of the drug similarly. This description includes feelings of euphoria, increased energy, talkative, and mentally alert. It can also temporarily decrease the need for food and sleep (Siegel, 1984). Cocaine use has repeatedly been associated with an increased risk of committing a crime once a user has taken the drug. Therefore, it becomes imperative to research whether or not the similarities of cocaine and methamphetamine transcend into whether using methamphetamine also increases the risk of the user to commit a crime.

The differences in the effects of cocaine and methamphetamine use are firstly, the way in which the body mechanisms respond to the drug once it has entered the body.

"Although their overall actions are similar, there is a fundamental difference in the mechanisms by which amphetamine and cocaine increase neurotransmitter 
levels in the synaptic cleft. Cocaine appears to inhibit the removal of transmitter that is released by neuronal activity (Fig. 2) and its action is dependent on extracellular [Ca.sup.2+] [20], whereas amphetamine causes transmitter to be transported extraneuronally (Beebe \& Walley, 1995, p. 449).

Secondly, there are psychopharmacological differences between crack and methamphetamine use. In contrast to crack, methamphetamine produces a longer lasting high. As a result, methamphetamine users are able to remain away from the market environment longer as they are not constantly "chasing the pipe" (Lattimore, 1997). It is imperative to study whether or not these differing effects transcend into the risk of committing a crime once a user has taken the drug. Therefore, these contradictory findings suggest the drug/crime nexus may be different for methamphetamine than for cocaine.

Lastly, methamphetamine and cocaine differ in street price. Methamphetamine is cheaper than cocaine and crack cocaine for that matter according to the Institute for Defense Analysis (2008), Estimated the Annual Price per Expected Pure Gram of Methamphetamine in various Cities, Retail Level (0.1 - $1.0 \mathrm{~g}$, Evaluated at $0.3 \mathrm{~g})$, Constant 2007 Dollars ranges from $\$ 16.10$ to $\$ 139.13$ depending on the purity level. In comparison, the street price of cocaine ranges from $\$ 51.62$ to $\$ 304.66$ depending on the purity level. The street price of crack cocaine ranges from $\$ 61.23 \$ 318.20$ depending on the purity level. Therefore, it is not only cheaper to buy methamphetamine but the drug results in a longer lasting high than cocaine. 


\section{Cocaine Use and Crime (Violent, Property, Drug Sales)}

Since 1980, cocaine has received more attention from researchers than any other nonnarcotic drug. The comparisons and distinguishing differences have been cited regarding the effects of cocaine and methamphetamine on a user in several previous studies ((Beebe \& Walley, 1995; Lattimore, 1997; Rawson et al., 2000; Garlow et al., 2002; Glasner-Edwards, 2008; Chitwood et al., 2009). Therefore, it is essential to study both the common and differing effects these drugs may have on their user, specifically regarding criminal behavior both violent, property related and drug sale crimes.

Several studies of cocaine users from these two subject sources have associated cocaine use with high crime rates overall. One such study conducted by Johnson, Wish and Huizinga (1993) offer strong support for a cocaine and crime association. In an analysis of data involving a nationwide sample of approximately 1,500 adolescents, subjects reporting cocaine use, who represented only $1.3 \%$ of the sample, accounted for $40 \%$ of all serious crime committed by the sample. In another study of the cocaine and crime association, involving over 3500 drug abuse clients in 27 states. Collins et al. (1985) found that frequency of cocaine use was strongly associated with the commission of income-generating crime. Additional research shows that narcotic addicts greatly increase their level of criminal offending during periods of elevated narcotic use (Anglin \& Speckart, 1988). McGlothlin (1978) has shown that income from property crime escalates with increasing narcotic use. However, further research does not show that same results for other non-property crimes (Anglin \& Speckart, 1998). 


\section{Marijuana Use and Crime (Violent, Property and Drug Sales)}

Marijuana is the most frequently used illegal drug according to the 2011 National Survey on Drug Use and Health. Additionally, states such as Massachusetts and Colorado have decriminalized the use of marijuana are small amounts, while Washington is in the process of legalizing its use. The need for research on the associations between marijuana use and crime is essential.

According to some research, there is no unequivocal evidence that marijuana use causes violent behavior. In two separate reviews (Gandossy et al., 1980; Wish \& Johnson, 1986), evidence linking marijuana use to crime was found to be weak. Additionally, there is virtually no research indicating an association between marijuana use and crime for economic gain (Harrison \& Gfroerer, 1992). Marijuana however, is low in cost and easily attainable from small time dealers in comparison to cocaine which research shows is associated with property crime (Anglin \& Speckhart, 1988).

Drug selling is the only crime that has shown a significant association between marijuana use and crime. Marijuana use was not associated with increased criminal activity, except for the sale of drugs (Wish \& Johnson, 1986). Since marijuana users are frequently multiple drug users, however, it is difficult to isolate the criminogenic effects of any one substance (Wish \& Johnson, 1986). 


\section{Chapter 3. Hypotheses}

H1: H1: Respondents who reported cocaine use within the past 12 months will have an increased risk of committing a violent crime within the past 12 months in comparison to non-cocaine users.

$\mathrm{H} 2: \mathrm{H} 2$ : Respondents who reported marijuana use within the past 12 months will not have an increased risk committing a violent crime within the past 12 months in comparison to non-marijuana users.

H3: H3: Respondents who reported methamphetamine use within the past 12 months will have an increased risk of committing a violent crime within the past 12 months in comparison to non-methamphetamine users.

H4: H4: Methamphetamine use reported in the last 12 months will not be associated with committing a property crime within the past 12 months.

H5: H5: Marijuana use reported in the last 12 months will not be associated with committing a property crime within the past 12 months.

H6: H6: Respondents who reported cocaine use in the last 12 months will have an increased risk of committing a property crime within the past 12 months.

H7: H7: Respondents who reported cocaine use within the past 12 months will have an increased risk of selling drugs within the past 12 months.

H6: H6: Respondents who reported methamphetamine use within the past 12 months will have an increased risk of selling drugs within the past 12 months. 
H8:H8: Respondents who reported marijuana use within the past 12 months will have an increased risk of selling drugs within the past 12 months. 


\section{Chapter 4. Methodology}

The research design is a quantitative approach which uses secondary data analysis of the National Longitudinal Survey of Adolescent Health (Add Health). It is a nationally representative sample of adolescents in grades 7 through 12 in the US in the 1994-95 school year. The data set analyzed is Wave III of the 2008 National Longitudinal Survey on Adolescent Health. Wave III was chosen for analysis respondents were of the appropriate for drug use and the age crime curve. The age crime curve increases throughout teen years and then decreases once an individual enters their twenties (Farrington, 1986). According to previous research, person crimes peak later than property crimes, and the rate declines more slowly with age. The peak years for person and property offenses in self-report data are the mid- teens, which are also the peak years for property offenses in official data. In contrast, person offenses in official data peak in the late teens or early twenties (Hirschi \& Gottfredson 1983). Additionally, the prevalence of drug use increases rapidly during adolescence and then decreases over time. According to Chen and Kandel, most drug use is both initiated and stopped before an individual's late 20s (1995). Therefore, using Wave III data where respondents are aged 18-26 encompasses the time before drug initiation and use declines and the peak age for violent crime while also accounting for the tail end of the peak age of property crime. During Waves I and II the respondents were at too young of an age where the frequency of drug use would be high enough to use for analysis purposes.

The Wave III public access version of the survey was chosen because of its generalizability. It is a nationally representative longitudinal survey of adolescent health 
in the United States. This coupled with the fact that it has specific questions that are of theoretical interest for this project. The public access survey is the only version available for public use. The public access version of the survey limits the number of respondents to 4,882 of the original Wave I respondents, 12,105 who were then re-interviewed between August 2001 and April 2002 for the Wave III study. Wave III respondents were between 18 and 26 years old. Using this survey, the relationship between illegal drug use, and criminal behavior is explored.

The first wave of the National Longitudinal Survey on Adolescent Health was conducted in 1995. The primary sampling frame for Add Health is a database collected by Quality Education Data, Inc. Systematic sampling methods and implicit stratification ensure that the 80 high schools selected are representative of US schools with respect to region of country, urbanicity, size, type, and ethnicity. Eligible high schools included an 11th grade and enrolled more than 30 students. More than 70 percent of the originally sampled high schools participated in Wave III. The recruitment effort resulted in a pair of schools in each of 80 communities

The In-School Questionnaire, a self-administered instrument formatted for optical scanning, was administered to more than 90,000 students in grades 7 through 12 in a 45to 60-minute class period between September 1994 and April 1995. There was no "makeup" day for absent students. Parents were informed in advance of the date of the questionnaire and could direct that their children not participate. All students who completed the In-School Questionnaire plus those who did not complete a questionnaire but were listed on a school roster were eligible for selection into the core in-home 
sample. Students in each school were stratified by grade and sex. About 17 students were randomly chosen from each stratum so that a total of approximately 200 adolescents were selected from each of the 80 pairs of schools. A total core sample of 20,745 adolescents participated in the In-Home interviews. The second wave of In-home interviews surveyed almost 15,000 of the same students one year after the first wave.

During Wave III Interviews with 15,197 Wave I respondents were conducted in 2001 and 2002. The Wave III sample consists of Wave I participants who could be located and interviewed. A respondent did not have to participate in Wave II to qualify for participation in Wave III. Wave III also collected High School Transcript Release Forms as well as samples of urine (for sexually transmitted infections) and saliva (for HIV testing and, for full siblings and twins, DNA extraction). The data set was weighted using the binge sample variable in order to correct the over sampling of certain minority populations.

\section{Dependent Variables:}

Dependent Variable: For the purpose of this study the dependent variables will be conceptualized with regard to the drug crime nexus (Goldstein, 1985). The logic is that different drugs will likely produce different effects on users and their likelihood of engaging in the different types of crimes that compose the drug-crime nexus. Goldstein's drug crime nexus states that crime from drug use can be categorized into 3 different models. The first model defined as systematic crime deals with criminal behavior which stems from the manufacturing and distribution of illegal drugs. The second model is 
defined as economic-compulsive crime. This model deals with drug users who steal in order to obtain money to finance the cost of their drug habit. The third group is drug users who commit crime because of some pharmacological reaction that a particular drug has with their body. Crime for this study will be operationalized as Drug Sale Crime, Property Crime and Violent crime.

\section{Drug Sale Crimes}

The Indicator of Drug Sale Crime was measured through Add Health self- report responses of one question:

In the past 12 months, did you sell marijuana or other illegal drugs?

This question was operationalized as a dichotomous variable ( $1=y e s)$.

\section{Property Crimes}

The Indicators of Non-Violent crime were measured through Add Health self- report responses of six Non-Violent criminal activities. These questions include:

In the past 12 months, did you steal something worth more than $\$ 50$ ?

In the past 12 months, did you steal something worth less than $\$ 50$ ?

In the past 12 months, did you go into a house or building to steal something?

In the past 12 months, did you buy, sell, or hold stolen property?

In the past 12 months, did you use someone else's credit card, bank card, or automatic teller card without their permission or knowledge?

These questions were combined and operationalized as a dichotomous variable (1=yes). 


\section{Violent Crime}

The indicators of Violent Crime were measured through statistical analysis of Add Health responses to these six questions:

In the past 12 months, did you use or threaten to use a weapon to get something from someone?

In the past 12 months, did you take part in a physical fight where a group of your friends was against another group?

In the past 12 months, did you use a weapon in a fight?

In the past 12 months, did you hurt someone badly enough in a physical fight that he or she needed care from a doctor or nurse?

In the past 12 months, have you been involved in a physical fight while on drugs?

In the past 12 months, have you pulled a knife or gun on someone?

In the past 12 months, have you shot or stabbed someone?

These questions were combined and operationalized as a dichotomous variable (1=yes).

\section{Independent Variables:}

\section{Methamphetamine Use}

The indicators of Methamphetamine Use were measured through the question on the Add Health survey which states: "In the past year have you used methamphetamine?" Methamphetamine Use was operationalized for the purpose of the research study as a dichotomous variable in which $1=$ Yes, the respondent had used methamphetamine within the past year and $0=$ No the respondent had not used methamphetamine within the past year. 


\section{Cocaine Use}

The indicators of Cocaine Use were measured through the question on the Add Health survey which states: "In the past year have you used cocaine?" Cocaine Use was operationalized for the purpose of the research study as a dichotomous variable in which $1=$ Yes, the respondent had used cocaine within the past year and $0=$ No the respondent had not used cocaine within the past year.

\section{Marijuana Use}

The indicators of Marijuana Use were measured through the question on the Add Health survey which states: "In the past year have you used marijuana?" Marijuana Use was operationalized for the purpose of the research study as a dichotomous variable in which $1=$ Yes, the respondent had used marijuana within the past year and $0=$ No the respondent had not used marijuana within the past year.

Interaction of Cocaine Use and Methamphetamine

The indicators of Cocaine Use and Methamphetamine were measured through the question on the Add Health survey which states:

In the past year have you used cocaine?

In the past year have you used methamphetamine?

Coded as a dichotomous variable:

$1=$ Yes, used BOTH methamphetamine and cocaine within the past 12 months. 
$0=$ No, Did not use meth OR cocaine within the past 12 months.

\section{Control Variables}

Control variables conceptualized as cohabitation, gender, previously arrested and education were used due to previous research which has demonstrated that they have a relationship with criminal activity. Cohabitation is used for two reasons. The first reason references the "aging out effect", where as an individual ages out of crime they make particular life choices which encourage them to take legal jobs and stay out the prison system. When a person gets married and starts a family they begin to think of their family's need above their own and begin to make life choices that are more mainstream and socially acceptable. For example, seeking treatment for a drug problem or obtaining legal employment as opposed to drug dealing as a source of income (Matza, 1964; Sampson et al 2006). Secondly, it has been suggested that potential biological effects of methamphetamine may be intensified by situational circumstances. If a person is living alone they may not be aware of how their methamphetamine use is affecting their mental well -being. They may develop psychotic symptoms such as hallucinations and without another individual present to cross-check whether or not what they are seeing is real they may begin to act upon those hallucinations and delve deeper into the psychosis. In a review of the drug violence relationship literature, Parker and Auerhahn (1998) noted that a lack of social interaction may increase the chances for amphetamine-related violence because users are unable to "cross-check" their behavior with other individuals who cohabitate with them. However Gender is used as a control variable because on average males are more likely in comparison to females to use illegal drugs and commit crimes 
(Pennell, 1999; Hendelang, Hirschi, \& Weiss, 1981). Education is negatively associated with drug use and crime. In essence, the more education a person receives the less likely they are to commit crimes or use drugs (Lochner \& Moretti 2004). Whether or not an individual had been arrested is used because once an individual has experience with the criminal justice system they are more likely to commit another crime in comparison to those who have never been arrested (Freeman, 2003).

Additionally other drug variables such as cocaine use and marijuana use were to be controlled for because previous research has indicated a relationship between using these illegal drugs and violent behavior (Putnins 2003, Uggen and Thompson 2003, Cartier et al 2006). Additionally, the use of multiple drugs at the same time, or poly-drug use, which includes the use of any of the illegal drugs stated above in combination with methamphetamine, may affect the association between methamphetamine use and crime. 


\section{Chapter 5. Analysis}

Table 1: Univariate Analysis

\begin{tabular}{|c|c|c|c|c|}
\hline Category & Levels & $\mathbf{N}$ & Valid\% & SD \\
\hline \multicolumn{5}{|l|}{ Dependent (Past 12 mths) } \\
\hline \multirow[t]{3}{*}{ Violent Crime } & & 4801 & & .3474 \\
\hline & $1=$ Yes & 674 & $14.0 \%$ & \\
\hline & $0=$ No & 4127 & $86.0 \%$ & \\
\hline \multirow[t]{3}{*}{ Property Crime } & & 4812 & & .3895 \\
\hline & $1=$ Yes & 897 & $18.6 \%$ & \\
\hline & $0=\mathrm{No}$ & 3915 & $81.4 \%$ & \\
\hline \multirow[t]{3}{*}{ Drug Sales Crime } & & 4821 & & .2632 \\
\hline & $1=$ Yes & 361 & $7.5 \%$ & \\
\hline & $0=\mathrm{No}$ & 4460 & $92.5 \%$ & \\
\hline
\end{tabular}

Independent (Past 12 mths)

Methamphetamine Use

$1=$ Yes

$0=$ No

4759

$97.5 \%$

Cocaine Use

4882

.2398

$1=$ Yes

299

$6.1 \%$

$0=$ No

4583

$93.9 \%$

Marijuana Use

4880

.4661

$1=$ Yes

1556

$31.9 \%$

$0=$ No

3324

$68.1 \%$

Meth/Coc Use

4881

.1254

$\begin{array}{lrr}1=\text { Yes } & 78 & 1.6 \% \\ 0=\text { No } & 4803 & 98.4 \%\end{array}$

National Longitudinal Survey on Adolescent Health 2008 


\section{Control}

\section{$\underline{\text { Education (0=High School Diploma) }}$}

Drop-Out

4882

.2465

$\begin{array}{lrr}1=\text { Yes } & 617 & 12.6 \% \\ 0=\text { No } & 4262 & 87.4 \%\end{array}$

Currently in School

4875

.4842

$1=$ Yes

1828

$37.5 \%$

$0=\mathrm{No}$

3047

$62.5 \%$

GED Received

4877

.2632

$1=$ Yes

365

$7.5 \%$

$0=\mathrm{No}$

4512

$92.5 \%$

High School Diploma

4875

.3119

$$
1=\text { Yes }
$$

4045

$82.9 \%$

$0=$ No

830

$17.1 \%$

College Degree

4879

.3859

$\begin{array}{lrr}1=\text { Yes } & 888 & 18.2 \% \\ 0=\text { No } & 3991 & 81.8 \%\end{array}$

$\underline{\text { Race }(0=\text { White })}$

White

4882

.4169

$$
\begin{aligned}
& 1=\text { Yes } \\
& 0=\text { No }
\end{aligned}
$$

3376

$69.2 \%$

1506

$30.8 \%$

Black

4882

.4322

$\begin{array}{lll}1=\text { Yes } & 1213 & 24.8 \% \\ 0=\mathrm{No} & 3669 & 75.2 \%\end{array}$

National Longitudinal Survey on Adolescent Health 2008 


\section{Category}

Hispanic

American Indian

Asian$$
0=\mathrm{No}
$$

$1=$ Yes

$0=\mathrm{No}$

$1=$ Yes

$0=\mathrm{No}$

Levels

$N$

Valid\%

SD

4882

.2104

522

4360

4882

.2105

226

4656

4882

.2105

$$
1=\text { Yes }
$$

227

4655

4843

529

4314

4629

Cohabitation

Gender

$$
\begin{aligned}
& 1=\text { Yes } \\
& 0=\mathrm{No}
\end{aligned}
$$

$$
1=\text { Yes }
$$

432

4197

4882

2629

2253

$1=$ Female

$0=$ Male

National Longitudinal Survey on Adolescent Health 2008 
In table 1, the frequencies, standard deviations and valid percentages of the dependent, independent and control variables are displayed. Property crimes are displayed has having the highest frequency of yes responses at 897 . Therefore, $18.6 \%$ of the respondents admitted to having committed a property crime within the past 12 months. The frequency of respondents who admitted to committing a violent crime within the past 12 months is 674 . Therefore, $14 \%$ of the respondents admitted to committing a violent crime within the past 12 months. The frequency of drug sale crimes is about half of the frequency of violent crimes, 361 . Therefore, $7.5 \%$ of respondents admitted to selling drugs within the past 12 months.

Marijuana is most frequently used drug in comparison to methamphetamine and cocaine according to the National Longitudinal Survey of Adolescent Health 2008. 1556 respondents admitted to using marijuana within the past 12 months. Therefore, $31.0 \%$ of the respondents admitted to using marijuana within the past 12 months. 299 respondents admitted to using cocaine within the past 12 months. Therefore, $6.1 \%$ of the respondents admitted to having used cocaine within the past 12 months, while 120 respondents, $2.5 \%$, admitted to using methamphetamine within the past 12 months. Additionally, 78 or $1.6 \%$ of respondents admitted to using both methamphetamine and cocaine within the past 12 months. This means that of the 299 cocaine users, 221 used cocaine and not methamphetamine while only 42 out of the 120 methamphetamine users used methamphetamine and not cocaine. Therefore, the majority of methamphetamine users were also using cocaine in addition to methamphetamine, while the majority of cocaine users did not use methamphetamine. 
The majority of respondents, (4045), received a high school diploma with only (617) respondents admitting to dropping out of school before achieving a high school diploma. The majority of respondents were white (1213) with an over-representative number of respondents who were Black (1213). This was corrected during the analysis by weighting the data using the binge sample variable. $53.9 \%$ percent of the respondents were female while $46.1 \%$ of the respondents were male. The majority of respondents $(90.7 \%)$ reported living with someone else during the time of the survey. Additionally, $10.9 \%$ of the respondents admitted to being arrested sometime in their lifetime 
Table 2: Demographics of Methamphetamine users (within the past 12 months)

\begin{tabular}{llll} 
Category & Levels & $\mathrm{N}$ & Valid\% \\
\hline
\end{tabular}

$\underline{\text { Age (years) }}$

$19-20$

$\begin{array}{lrr}1=\text { Yes } & 120 & 30.8 \% \\ 0=\text { No } & 37 & 69.2 \%\end{array}$

21-22

120

$\begin{array}{lll}1=\text { Yes } & 47 & 39.2 \% \\ 0=\mathrm{No} & 73 & 60.8 \%\end{array}$

$23-24$

120

$\begin{array}{lll}1=\text { Yes } & 32 & 26.6 \% \\ 0=\text { No } & 88 & 73.4 \%\end{array}$

25-26

120

$\begin{array}{lrr}1=\text { Yes } & 4 & 3.3 \% \\ 0=\mathrm{No} & 116 & 96.7 \%\end{array}$

$\underline{\text { Education }}$

Drop-Out

120

$\begin{array}{lll}1=\text { Yes } & 26 & 21.7 \% \\ 0=\mathrm{No} & 94 & 78.3 \%\end{array}$

Currently in School

120

$\begin{array}{lll}1=\text { Yes } & 35 & 29.2 \% \\ 0=\mathrm{No} & 85 & 78.8 \%\end{array}$

GED Received

120

$\begin{array}{lrr}1=\text { Yes } & 13 & 10.8 \% \\ 0=\mathrm{No} & 107 & 89.2 \%\end{array}$

National Longitudinal Survey on Adolescent Health 2008 


\section{Category}

High School Diploma

College Degree

$$
\begin{aligned}
& 1=\text { Yes } \\
& 0=\text { No }
\end{aligned}
$$$$
1=\text { Yes }
$$$$
0=\text { No }
$$$$
0=\mathrm{No}
$$

$\underline{\text { Race }(0=\text { White })}$

White

$$
\begin{aligned}
& 1=\text { Yes } \\
& 0=\text { No }
\end{aligned}
$$

Black

$$
\begin{aligned}
& 1=\text { Yes } \\
& 0=\mathrm{No}
\end{aligned}
$$

Hispanic

$$
\begin{aligned}
& 1=\text { Yes } \\
& 0=\mathrm{No}
\end{aligned}
$$

American Indian

$$
\begin{aligned}
& 1=\text { Yes } \\
& 0=\mathrm{No}
\end{aligned}
$$

Asian

$$
\begin{aligned}
& 1=\text { Yes } \\
& 0=\text { No }
\end{aligned}
$$

$\mathbf{N}$

120

50

$41.7 \%$

70

$58.3 \%$

120

7

113

$5.8 \%$

\begin{tabular}{|c|c|}
\hline 13 & $10.8 \%$ \\
\hline 107 & $89.2 \%$ \\
\hline
\end{tabular}

$94.2 \%$

120

96

$80.0 \%$

24

$20.0 \%$

120

12

$10.0 \%$

108

$90.0 \%$

120

120

18

$15.0 \%$

102

$85.5 \%$

120

National Longitudinal Survey on Adolescent Health 2008 
Category

Control Variables

Ever Arrested

Cohabitation

Gender

$1=$ Female

$0=$ Male

$1=$ Yes

$0=\mathrm{No}$

0-Male

$1=$ Yes

$0=$ No

$$
\text { (1) }
$$

$1=$ Female
$0=$ Male

National Longitudinal Survey on Adolescent Health 2008
Valid\%

120

$\begin{array}{ll}43 & 64.2 \% \\ 77 & 35.8 \%\end{array}$

119

$105 \quad 88.2 \%$

$14 \quad 11.8 \%$

120

$44 \quad 36.7 \%$

$76 \quad 63.3 \%$

In Table 2, the frequencies and valid percentages are displayed specifically for those respondents who had used methamphetamine within the past 12 months. The majority of methamphetamine users, $96 \%$ were between the ages of $19-24$. The highest frequency of responses for meth users was for the ages 21-22 during the time of the survey. $39 \%$ of the meth using respondents were aged $21-22$ during the time of the survey. The least frequent ages recorded for meth using respondents were 25-26 years of age. These results are consistent with literature that claims methamphetamine use is now becoming more of young adult drug (Penell, 1999).

The majority of methamphetamine users is not currently enrolled in school and had not received a college degree. However, it is important to note that the majority of 
methamphetamine users did not drop out of high school. Therefore, GED and High School diploma received are combined; the majority of methamphetamine users, $60.8 \%$ received a high school diploma or GED.

The majority of methamphetamine users, $80 \%$, are white. These are not mutually exclusive and therefore respondents were allowed to choose more than one race to describe themselves. Additionally, the majority, $63.3 \%$ of the methamphetamine users were male. The majority, $88.2 \%$, of meth using respondents live with someone else during the time this survey was completed. These results support previous literature which claims that white males are more likely to use methamphetamine than minorities or females (Pennel, 1999). Additionally, the majority of methamphetamine users had been arrested in their lifetime, $64 \%$ of methamphetamine users had been arrested sometime during their lifetime.

(Figures not shown).The demographics of cocaine users are very similar to methamphetamine users. The majority of cocaine users (64.5\%) were 22 years of age or younger. The most frequently reported age for cocaine users was, 22, years old. In comparison to methamphetamine users, the majority of cocaine users $57.9 \%$ did not obtain a high school diploma or a GED. The majority of cocaine users are also not currently enrolled in school. The majority of cocaine users, (259) reported white as their race, while $63.5 \%$ of cocaine users were male. Additionally, the majority of cocaine users, $61.9 \%$ had never been arrested during their lifetime. 
(Figures not shown). The demographics for marijuana users are consistent with those of methamphetamine and cocaine users. For marijuana users the majority, $(66.8 \%)$ are 22 years of age or younger with the most frequently reported age being 22 years. The majority of marijuana users, $75.2 \%$, are white and male $54.5 \%$. 
Table 3: Illegal Drug Usage (past 12 mths) and Its Impact on Drug Sales Crime (in past 12 mths)

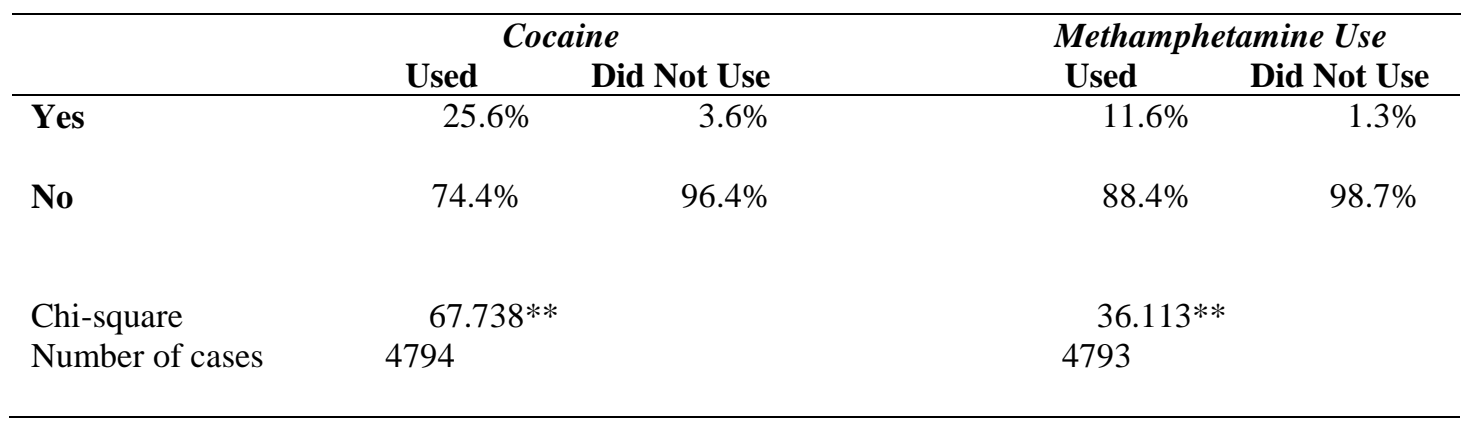

Source: National Longitudinal Survey on Adolescent Health 2008

$* \mathrm{p}<0.05 . * * \mathrm{p}<0.01$

Table 3 presents the results of a crosstab. As illustrated in table 3 drug usage within the past year did have an impact on whether or not the respondent sold drugs within the past 12 months. According to the table above, respondents who had used cocaine were $22 \%$ more likely to sell drugs than respondents who did not use cocaine within the past 12 months. Additionally, respondents who used methamphetamine within the past 12 months were $10.3 \%$ more likely to sell drugs within the past 12 months than those respondents who did not use methamphetamine. However, the majority of cocaine users, $74.4 \%$ and the majority of methamphetamine users $88.4 \%$ did not report selling drugs within the past 12 months. The results regarding cocaine use were significant and are supported by the literature previously discussed (Sommers \& Baskin, 2006).

The results regarding methamphetamine use were also significant. These support literature previously discussed (Gizzi \& Gerkin, 2009). Gizzi and Gerkin’s (2009) study found that methamphetamine users were most likely to have their charges involve drug offenses, in comparison to property crime charges and violent crime charges. 
Table 4: Illegal Drug Usage (past 12 mths) and Its Impact on Property Crime (in past 12 mths)

\begin{tabular}{|c|c|c|c|c|}
\hline \multirow{3}{*}{$\begin{array}{l}\text { Yes } \\
\end{array}$} & \multicolumn{2}{|c|}{ Cocaine } & \multicolumn{2}{|c|}{ Methamphetamine Use } \\
\hline & Used & Did Not Use & Used & Did Not Use \\
\hline & $41.2 \%$ & $18.1 \%$ & $40.0 \%$ & $19.5 \%$ \\
\hline No & $58.8 \%$ & $81.9 \%$ & $60.0 \%$ & $80.5 \%$ \\
\hline Chi-square & $48.614^{*}$ & & 19.659 & \\
\hline Number of cases & 4794 & & 4793 & \\
\hline
\end{tabular}

Source: National Longitudinal Survey on Adolescent Health 2008

$* \mathrm{p}<0.05 . *{ }^{*} \mathrm{p}<0.01$

Table 4 presents the results of a crosstab. As illustrated in table 4 drug usage within the past year did have an impact on whether or not the respondent committed a non-violent crime within the past 12 months. According to the table above, respondents who had used cocaine were $23.7 \%$ more likely to commit a property crime than respondents who did not use cocaine within the past 12 months. Additionally, respondents who used methamphetamine within the past 12 months were $20.5 \%$ more likely to commit a property crime within the past 12 months than those respondents who did not use methamphetamine. However, the majority of cocaine users, $58.8 \%$ and the majority of methamphetamine users $60 \%$ did not report committing a property crime within the past 12 months. The results regarding cocaine use were significant and are supported by the literature previously discussed (Nurco et al., 1989, Harrison \& Gfroerer, 1992).

The results regarding methamphetamine use were also significant. These results both support and contradict the literature previously discussed (Sommer \& Baskin, 2006, 
Gizzi \& Gerkin, 2009). These results contradict Sommers and Baskin's (2006) study, which states that methamphetamine, is too cheap and easily accessible for individuals to steal in order to fund their drug habit. However, these results do support Gizzi and Gerkin's (2009) study, which found that the second largest category of responses for arrest charges was property crimes among methamphetamine users. Methamphetamine users who were arrested were more likely to be arrested for drug possession or property crime than for violent crime (Gizzi \& Gerkin, 2009). 
Table 5: Illegal Drug Usage (past 12 mths) and Its Impact on Violent Crime (in past 12 mths)

\begin{tabular}{|c|c|c|c|c|}
\hline & & & Metham & mine Use \\
\hline & Used & Did Not Use & Used & Did Not Use \\
\hline Yes & $46.0 \%$ & $14.9 \%$ & $40.0 \%$ & $16.2 \%$ \\
\hline No & $54.0 \%$ & $85.1 \%$ & $60.0 \%$ & $83.8 \%$ \\
\hline Chi-square & 32.605 & & 7.945 & \\
\hline Number of cases & 4801 & & 4800 & \\
\hline
\end{tabular}

Source: National Longitudinal Survey on Adolescent Health 2008

$* \mathrm{p}<0.05 . * * \mathrm{p}<0.01$

Table 5 presents the results of a crosstab. As illustrated in table 5 drug usage within the past year did have an impact on whether or not the respondent committed a violent crime within the past 12 months. According to the table above, respondents who had used cocaine were $31.1 \%$ more likely to commit a violent crime than respondents who did not use cocaine within the past 12 months. Additionally, respondents who used methamphetamine within the past 12 months were $23.8 \%$ more likely to commit a violent crime within the past 12 months than those respondents who did not use methamphetamine. However, the majority of cocaine users, $54 \%$ and the majority of methamphetamine users, $60 \%$ did not report committing a violent act within the past 12 months. These results were statistically significant and supported by the literature discussed previously (Glasner-Edwards 2008, Sommers \& Baskin 2006, Cartier, Farabee \& Prendergast 2005, Garlow et al. 2002, Pennel et al., 1999), which suggests that cocaine and methamphetamine have similar but not identical mechanisms of action and share common psychiatric and psychosocial consequences and therefore their usage and its impact on violent crime is supported by this bivariate analysis. 
Table 6: Drug Sale Crimes

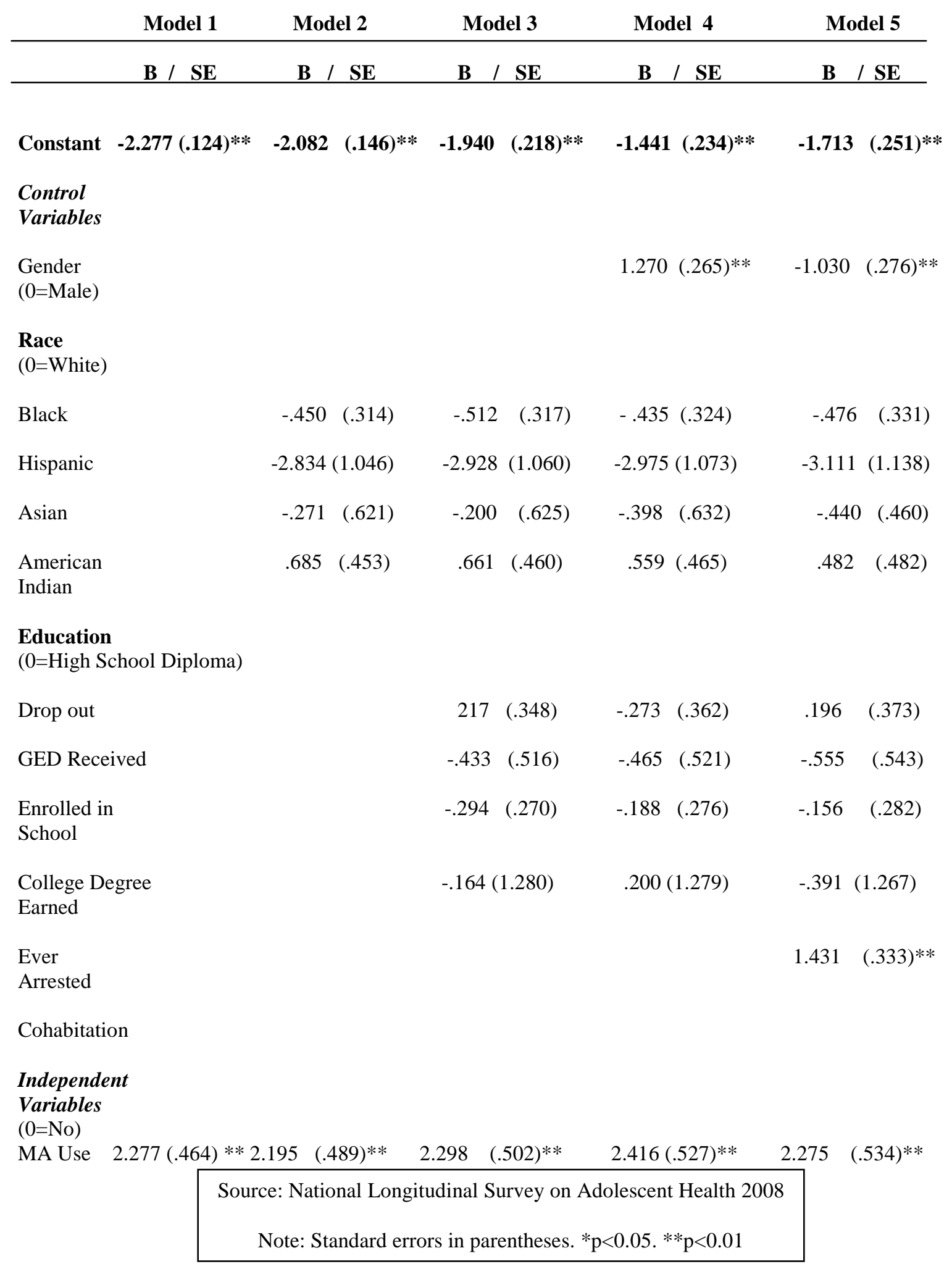




\begin{tabular}{|c|c|c|c|c|c|c|c|}
\hline & \multicolumn{2}{|c|}{ Model 6} & \multicolumn{2}{|c|}{ Model 7} & \multicolumn{2}{|c|}{ Model 8} & \multirow{2}{*}{$\begin{array}{c}\text { Model } 9 \\
\text { B / SE } \\
\end{array}$} \\
\hline & B / & SE & & / $\mathbf{S E}$ & & / $\mathbf{S E}$ & \\
\hline Constant & -1.741 & $(.253)^{* *}$ & -1.862 & $2(.259)^{* * *}$ & -3.329 & $9(.409)^{* * *}$ & $\overline{-3.329}(.409)^{* * *}$ \\
\hline \multicolumn{8}{|l|}{$\begin{array}{l}\text { Control } \\
\text { Variables }\end{array}$} \\
\hline $\begin{array}{l}\text { Gender } \\
(0=\text { Male })\end{array}$ & -.1 .019 & $(.277)^{* *}$ & -1.042 & $(.282)^{* *}$ & -.908 & $8(.301)^{* *}$ & $-.908(.302)^{* *}$ \\
\hline \multicolumn{8}{|l|}{$\begin{array}{l}\text { Race } \\
(0=\text { White })\end{array}$} \\
\hline Black & -.501 & $(.332)$ & -.389 & $9 \quad(.341)$ & -.198 & $(.371)$ & $-.199(.372)$ \\
\hline Hispanic & -3.092( & (1.136) & -.3 .166 & (.1.183) & -2.800 & $(1.178)$ & $-2.800(1.180)$ \\
\hline Asian & -.411 & $(.649)$ & -.295 & $(.646)$ & -.074 & $(.720)$ & $.074 \quad(.720)$ \\
\hline $\begin{array}{l}\text { American } \\
\text { Indian }\end{array}$ & .475 & (485) & .696 & $(.489)$ & -.718 & $(.553)$ & $.719 \quad(.555)$ \\
\hline \multicolumn{8}{|c|}{$\begin{array}{l}\text { Education } \\
(0=\text { High School Diploma) }\end{array}$} \\
\hline Drop out & .180 & $(.374)$ & .092 & $(.386)$ & -.191 & $(.415)$ & $-.191(.416)$ \\
\hline GED Received & -.518 & $(.545)$ & -.573 & $(.559)$ & -.261 & $(.597)$ & $-.262(.598)$ \\
\hline Enrolled in Schoo & $1-.172$ & $(.283)$ & -.233 & $(.287)$ & -.596 & $(.314)$ & $-.597(.315)$ \\
\hline $\begin{array}{l}\text { College Degree } \\
\text { Earned }\end{array}$ & .418 & (1.269) & .290 & (1.316) & -.424 & $(1.332)$ & $-.426(1.340)$ \\
\hline $\begin{array}{l}\text { Ever } \\
\text { Arrested }\end{array}$ & 1.447 & $(.334)^{* *}$ & 1.329 & $(.345)^{* *}$ & 1.035 & $(.375)^{* *}$ & $1.024(.375)^{* *}$ \\
\hline Cohabitation & .540 & $(.501)$ & .481 & $(.513)$ & -.475 & $(.536)$ & $.474(.536)$ \\
\hline \multicolumn{8}{|l|}{$\begin{array}{l}\text { Independent } \\
\text { Variables } \\
(0=\mathrm{No})\end{array}$} \\
\hline MA & 2.273 & $(.533)^{* *}$ & .814 & .640) & $.556($. & (.611) & .538 (1.292) \\
\hline Cocaine & & & 1.943 & $(.421)^{* *}$ & 1.035 & $(.423)^{*}$ & $1.033(.444)^{*}$ \\
\hline Marijuana & & & & & 2.764 & $(.386) * *$ & $2.764(.387)^{* *}$ \\
\hline Coc/MA Use & & & & & & & $.024 \quad(1.461)$ \\
\hline
\end{tabular}


Using the National Longitudinal Survey on Adolescent Health 2008, a logistic regression was performed to analyze the association between methamphetamine use in the past 12 months, cocaine use in the past 12 months, marijuana use in the past 12 months and drug sales committed within the past 12 months. The results of these analyses are reported in Table 6 . In model 1, the coefficient for methamphetamine use in the past 12 months is positive and significant $(\mathrm{p}=.000)$. The odds ratio for methamphetamine users in the past 12 months versus non-methamphetamine users is $\exp (2.277)=9.747$. This implies that the odds of selling drugs within the past 12 months is 9.747 times as likely for methamphetamine users as it is for non-methamphetamine users. Methamphetamine use within the past 12 months increases the likelihood of selling illegal drugs within the past 12 months in comparison to those who did not use methamphetamine within the past 12 months.

In model 2, race, which includes Black, Hispanic, Asian, American Indian and White as the reference category, was controlled for. The coefficient for methamphetamine use in the past 12 months remains positive and significant $(\mathrm{p}=.010)$. This implies that the odds of selling drugs within the past 12 months is 8.980 times as likely for methamphetamine users as it is for non-methamphetamine users. The control variable race is non-significant.

In model 3, education, which includes high school drop-out, currently enrolled in school, GED received, 4 year bachelor's degree or higher received and high school diploma received as the reference category is added. The coefficient for methamphetamine use in the past 12 months is positive and significant $(\mathrm{p}=.000)$. This implies that the odds of selling drugs within the past 12 months is 9.954 times as likely 
for methamphetamine users as it is for non-methamphetamine users. The coefficient for education is non-significant.

In model 4, gender is added, the reference category is male. The coefficient for gender is negative and also significant $(\mathrm{p}=.000)$. The odds ratio for females versus males is $\exp (1.270)=3.560$. The coefficient is negative, therefore $1.000-3.560=2.560$, which provides the odds ratio for males versus females. This implies that the odds of selling drugs within the past 12 months is 2.560 times as likely for male respondents as it is for female respondents. The coefficient for methamphetamine use within the past 12 months remains positive and significant $(\mathrm{p}=.000)$. The coefficient for methamphetamine use within the past 12 months increases when gender is added to this model. This implies that the odds of selling drugs within the past 12 months is 11.201 times as likely for methamphetamine users as it is for non-methamphetamine users.

In model 5, previously arrested was added to the model. The coefficient of ever arrested (in one's lifetime) is positive and statistically significant $(\mathrm{p}=.000)$ This implies that the odds of selling drugs within the past 12 months is 4.183 times as likely for respondents who have been arrested in their lifetime was as it is from respondents who have not been arrested sometime in their lifetime. Also, this addition affects the coefficient for methamphetamine use slightly. The coefficient for methamphetamine use drops from 2.416 to 2.275 . The coefficient for methamphetamine use remains positive and significant (.000). This implies that the odds of selling drugs within the past 12 months is 9.728 times as likely for methamphetamine users within the past 12 months as it is for non-methamphetamine users. 
In model 6 , cohabitation is added ( $1=$ Does not cohabit, lives alone). This addition does not affect the coefficient for methamphetamine use within the past 12 months remains, which remains positive and significant $(\mathrm{p}=.000)$. The addition of cohabitation does have an effect on the coefficient of ever arrested. The coefficient increases from 1.431 to 1.447 . The coefficient of ever arrested (in one's lifetime) is positive and statistically significant $(\mathrm{p}=.000)$ This implies that the odds of selling drugs within the past 12 months is 4.250 times as likely for respondents who have been arrested in their lifetime as it is for respondents who have not been arrested sometime in their lifetime. Gender remains negative and significant $(\mathrm{p}=.000)$. The coefficient for cohabitation is non-significant.

In model 7, cocaine use within the past 12 months is added. The coefficient for cocaine use within the past twelve months is positive and significant $(\mathrm{p}=.000)$. The coefficient of ever arrested (in one's lifetime) is positive and statistically significant $(\mathrm{p}=.000)$ This implies that the odds of selling drugs within the past 12 months is 6.979 times as likely for respondents who have used cocaine within the past 12 months as it is for respondents who have not used cocaine within the past 12 months. With the addition of cocaine use, methamphetamine use becomes non-significant. The coefficient of ever arrested (in one's lifetime) remains positive and statistically significant ( $\mathrm{p}=.000)$, however it does decrease. The coefficient drops from 1.447 to 1.329 . The coefficient of ever arrested (in one's lifetime) is positive and statistically significant $(\mathrm{p}=.000)$ This implies that the odds of selling drugs within the past 12 months is 3.778 times as likely for respondents who have been arrested in their lifetime as it is for respondents who have not been arrested sometime in their lifetime. The coefficient for gender is also affected by 
the addition of cocaine. The coefficient for gender is negative and significant $(p=.000)$. This implies that the odds of selling drugs within the past 12 months is 1.834 times as likely for respondents who used cocaine within the past 12 months as it is for respondents who have not used cocaine within the past 12 months.

In model 8, marijuana use within the past 12 months is added. The coefficient for marijuana use is positive and significant $(\mathrm{p}=.000)$. This implies that the odds of selling drugs within the past 12 months is 15.863 times as likely for respondents who have used marijuana within the past 12 months as it is for respondents who have not used marijuana within the past 12 months. The coefficient for cocaine use within the past twelve months remains positive and significant $(\mathrm{p}=.015)$. However, the coefficient for cocaine use does decrease dramatically from 1.943 to 1.035 once marijuana use is added to the model. This implies that the odds of selling drugs within the past 12 months is 2.813 times as likely for respondents who have used cocaine within the past 12 months as it is for respondents who have not used cocaine within the past 12 months The coefficient of ever arrested (in one's lifetime) is positive and statistically significant $(\mathrm{p}=.006)$. This implies that the odds of selling drugs within the past 12 months is 2.815 times as likely for respondents who have been arrested within the past 12 months as it is for respondents who have not been arrested within the past 12 months. Additionally, the coefficient for gender is affected when marijuana is added to the model. The coefficient for gender is negative and significant $(\mathrm{p}=.003)$. This implies that the odds of selling drugs within the past 12 months is 1.479 times as likely for male respondents as it is for female respondents. Methamphetamine use remains non-significant. 
In model 9, the interaction of methamphetamine use and cocaine use within the past 12 months is added to the model. The coefficient is non-significant. The coefficient for marijuana use is not affected. It remains positive and significant $(\mathrm{p}=.000)$. The coefficient for cocaine use is also not affected with this addition. It remains positive and significant $(\mathrm{p}=.020)$. The coefficient of ever arrested (in one's lifetime) remains positive and statistically significant $(\mathrm{p}=.006)$. The coefficient for gender remains negative and significant $(\mathrm{p}=.003)$. Methamphetamine use is still non-significant. 
Table 7: Property Crime Logistic Regressions

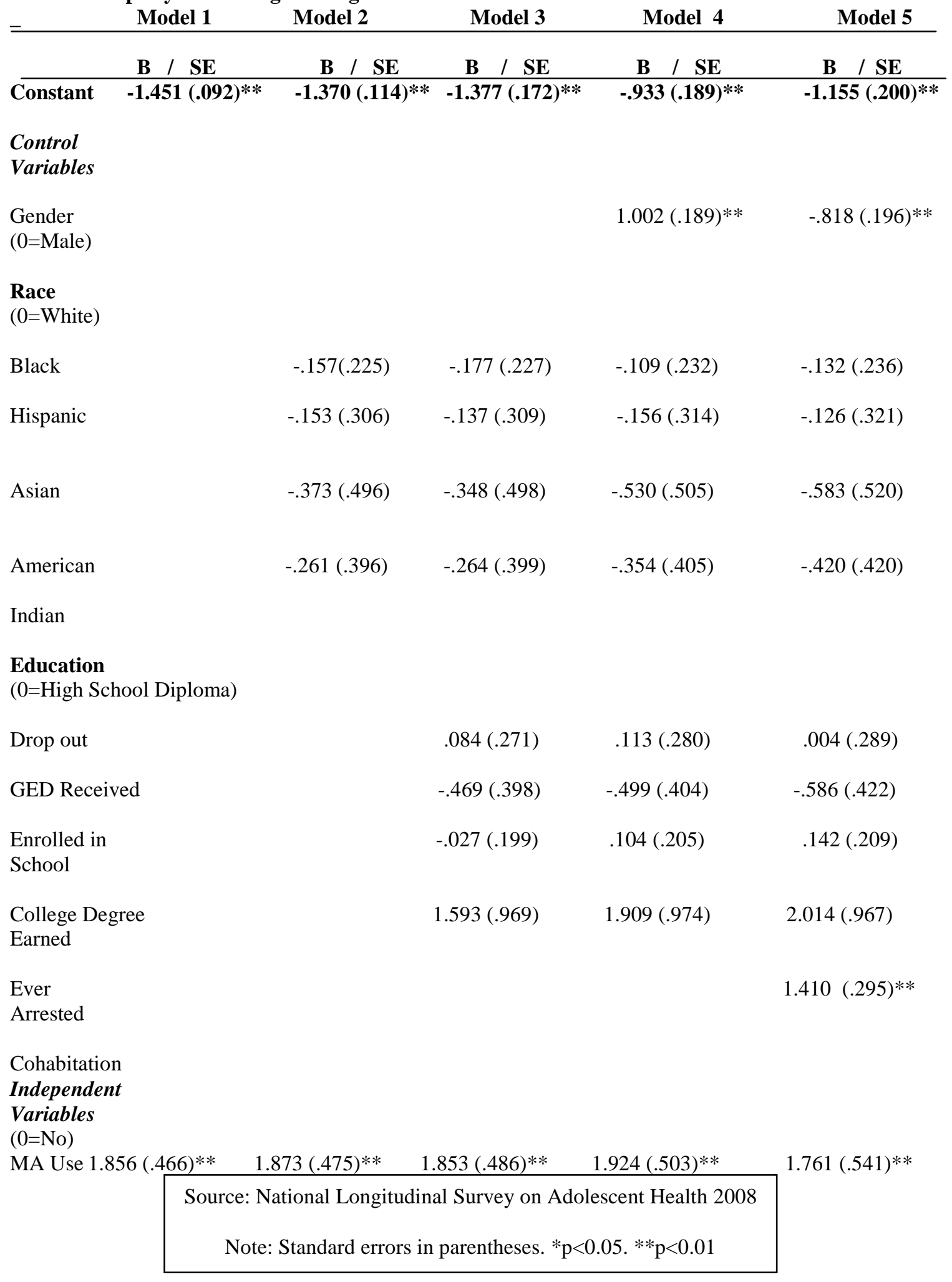




\begin{tabular}{|c|c|c|c|c|}
\hline & $\begin{array}{l}\text { Model } 6 \\
\text { B / SE }\end{array}$ & $\begin{array}{l}\text { Model } 7 \\
\text { B / SE }\end{array}$ & $\begin{array}{r}\text { Model } 8 \\
\text { B } \quad \text { SE }\end{array}$ & $\begin{array}{r}\text { Model } 9 \\
\text { B / SE }\end{array}$ \\
\hline$\overline{\text { Constant }}$ & $-1.178(.202)^{* *}$ & $-1.275(.206)^{* *}$ & $-1.618(.229)$ & $-1.617(.229)$ \\
\hline \multicolumn{5}{|l|}{$\begin{array}{l}\text { Control } \\
\text { Variables }\end{array}$} \\
\hline $\begin{array}{l}\text { Gender } \\
(0=\text { Male })\end{array}$ & $-.808(.197)^{* *}$ & $-.809(.199)^{* *}$ & $-.755(.202)^{* *}$ & $-.754(202)^{* *}$ \\
\hline \multicolumn{5}{|l|}{$\begin{array}{l}\text { Race } \\
(0=\text { White })\end{array}$} \\
\hline Black & $-.146(.237)$ & $-.062(.241)$ & $.014 \quad(.245)$ & $.011(.245)$ \\
\hline Hispanic & $-.114(.321)$ & $-.072(.323)$ & $-.057 \quad(.326)$ & $.059(.326)$ \\
\hline Asian & $-.562(.521)$ & $-.492(.519)$ & $-.388 \quad(.525)$ & $-.389(.525)$ \\
\hline $\begin{array}{l}\text { American } \\
\text { Indian }\end{array}$ & $-.432(.421)$ & $-.291(.422)$ & $-.291 \quad(.432)$ & $-.284 \quad(.433)$ \\
\hline \multicolumn{5}{|c|}{$\begin{array}{l}\text { Education } \\
(0=\text { High School Diploma })\end{array}$} \\
\hline Drop out & $-.002(.290)$ & $-.052(.296)$ & $-.121 \quad(.299)$ & $-.121(.299)$ \\
\hline GED Received & $-.564(.423)$ & $-.599(.430)$ & $-.460 \quad(.432)$ & $-.465(.433)$ \\
\hline Enrolled in School & $1.136(.209)$ & $.127(.197)$ & $.054 \quad(.215)$ & $.053 \quad(215)$ \\
\hline $\begin{array}{l}\text { College Degree } \\
\text { Earned }\end{array}$ & $2.037(.967)$ & $2.047(.979)$ & $1.916(.1 .005)$ & $1.905(1.008)$ \\
\hline $\begin{array}{l}\text { Ever } \\
\text { Arrested }\end{array}$ & $1.421(.295)^{* *}$ & $1.347(.301)^{* *}$ & $1.182(.307)^{* *}$ & $1.179(.308)^{* *}$ \\
\hline Cohabitation & $.379(.400)$ & $.343(.404)$ & $-.304(.404)$ & $.301 \quad(.404)$ \\
\hline \multicolumn{5}{|l|}{$\begin{array}{l}\text { Independent } \\
\text { Variables } \\
(0=\mathrm{No})\end{array}$} \\
\hline $\begin{array}{l}\text { MA } \\
\text { Use }\end{array}$ & $1.758(.514)^{* *}$ & $.667(.610)$ & $.479(.592)$ & $.241(.201)$ \\
\hline $\begin{array}{l}\text { Cocaine } \\
\text { Use }\end{array}$ & & $1.502(.373)^{* *}$ & $1.066(.381)^{*}$ & $1.038(.399)^{*}$ \\
\hline Marijuana & & & $955(.208) * *$ & $.919 \quad(.208) * *$ \\
\hline \multicolumn{5}{|l|}{ Use } \\
\hline Cocaine/MA Use & & & & .319 (1.377) \\
\hline
\end{tabular}


Using the National Longitudinal Survey on Adolescent Health 2008, a logistic regression was performed to analyze the association between methamphetamine use in the past 12 months, cocaine use in the past 12 months, marijuana use in the past 12 months and property crime committed within the past 12 months. The results of these analyses are reported in Table 7. In model 1, the coefficient for methamphetamine use in the past 12 months is positive and significant $(\mathrm{p}=.000)$. This implies that the odds of committing a property crime within the past 12 months is 6.398 times as likely for methamphetamine users as it is for non-methamphetamine users. Methamphetamine use within the past 12 months increases the likelihood of committing a property crime within the past 12 months in comparison to those who did not use methamphetamine within the past 12 months.

In model 2, race, which includes Black, Hispanic, Asian, American Indian and White as the reference category, was controlled for. The coefficient for methamphetamine use in the past 12 months remains positive and significant $(\mathrm{p}=.010)$. This implies that the odds of committing a property crime within the past 12 months is 6.507 times as likely for methamphetamine users as it is for non-methamphetamine users. The coefficient for race is non-significant.

In model 3, education, which includes high school drop-out, currently enrolled in school, GED received, 4 year bachelor's degree or higher received and high school diploma received as the reference category is controlled for. The coefficient for methamphetamine use in the past 12 months is positive and significant $(\mathrm{p}=.000)$. This implies that the odds of committing a property crime within the past 12 months is 6.378 
times as likely for methamphetamine users as it is for non-methamphetamine users. The coefficients for education are non-significant.

In model 4, gender is added, the reference category is male. The coefficient for gender is significant $(\mathrm{p}=.000)$. This implies that the odds of committing a property crime within the past 12 months is 1.724 times as likely for male respondents as it is for female respondents. The coefficient for methamphetamine use within the past 12 months is positive and significant $(\mathrm{p}=.000)$. The coefficient for methamphetamine use rises from 1.853 to 1.924 . This implies that the odds of committing a property crime within the past 12 months is 6.848 times as likely for methamphetamine users as it is for nonmethamphetamine users.

In model 5, previously arrested is added to the model. The coefficient of ever arrested (in one's lifetime) is positive and statistically significant $(\mathrm{p}=.000)$. This implies that the odds of committing a property within the past 12 months is 4.100 times as likely for respondents who have been arrested in their lifetime was as it is from respondents who have not been arrested sometime in their lifetime. The coefficient for methamphetamine use drops from 1.924 to 1.761 . This implies that the odds of committing a property crime within the past 12 months is 5.818 times as likely for methamphetamine users as it is for non-methamphetamine users. The coefficient for gender remains significant $(\mathrm{p}=.000)$. This implies that the odds of committing a property crime within the past 12 months is 1.263 times as likely for male respondents as it is for female respondents.

In model 6 , cohabitation is added ( $1=$ Does not cohabit, lives alone). Methamphetamine use within the past 12 months remains significant $(\mathrm{p}=.000)$. The 
coefficient of ever arrested (in one's lifetime) remains positive and statistically significant ( $\mathrm{p}=.000)$ and the coefficient for gender remains significant $(\mathrm{p}=.000)$. The coefficient for cohabitation is non-significant.

In model 7, cocaine use within the past 12 months is added. The coefficient for cocaine use within the past twelve months is positive and significant $(\mathrm{p}=.000)$. This implies that the odds of committing a property within the past 12 months is 4.491 times as likely for respondents who have used cocaine within the past 12 months as it is for respondents who have not used cocaine within the past 12 months. Methamphetamine use within the past 12 months becomes non-significant with the addition of cocaine use. The coefficient of ever arrested (in one's lifetime) remains positive and statistically significant $(\mathrm{p}=.000)$. The coefficient for gender is affected by this addition significant $(\mathrm{p}=.000)$. This implies that the odds of committing a property crime within the past 12 months is 1.127 times as likely for male respondents as it is for female respondents.

In model 8, marijuana use within the past 12 months is added. The coefficient for marijuana use within the past twelve months is positive and significant $(\mathrm{p}=.000)$. This implies that the odds of committing a property crime within the past 12 months is 2.597 times as likely for respondents who have used marijuana in the past 12 months as it is for respondents who have not used marijuana. Methamphetamine use within the past 12 months remains non-significant. The coefficient for cocaine use is affected by the addition of marijuana use within the past 12 months to the model. The coefficient drops from 1.502 to 1.066 . The coefficient remains positive and significant $(\mathrm{p}=.005)$. This implies that the odds of committing a violent crime within the past 12 months is 2.956 times as likely for respondents who used cocaine within the past 12 months as it is for 
respondents who have not used cocaine within the past 12 months. The coefficient of ever arrested (in one's lifetime) remains positive and statistically significant $(\mathrm{p}=.000)$. The coefficient of ever arrested remains is not dramatically effected and remains positive and significant $(\mathrm{p}=.000)$. The coefficient for gender remains significant $(\mathrm{p}=.000)$.

In model 9, the interaction of methamphetamine use and cocaine use within the past 12 months is added to the model. The coefficient is non-significant. The coefficient for marijuana use drops significantly from .955 to .919 but remains positive and significant $(\mathrm{p}=.000)$. This implies that the odds of committing a property crime within the past 12 months is 2.506 times as likely for respondents who have used marijuana in the past 12 months as it is for respondents who have not used marijuana. The coefficient for cocaine use drops from 1.066 to 1.038 and remains positive and significant. This implies that the odds of committing a property crime within the past 12 months is 2.824 times as likely for respondents who used cocaine within the past 12 months as it is for respondents who have not used cocaine within the past 12 months. The coefficient of ever arrested (in one's lifetime) remains positive and statistically significant $(\mathrm{p}=.000)$. The coefficient for gender remains negative and significant $(\mathrm{p}=.000)$. Methamphetamine use remains non-significant. 
Table 8: Violent Crime Logistic Regressions

\begin{tabular}{|c|c|c|c|c|c|}
\hline & Model 1 & Model 2 & Model 3 & Model 4 & Model 5 \\
\hline & $\mathrm{B} / \mathrm{SE}$ & B / SE & $\mathbf{B} / \mathbf{S E}$ & $\mathbf{B} / \mathrm{SE}$ & $\mathrm{B} / \mathrm{SE}$ \\
\hline Constant & $-1.193(.086) * *$ & $-1.062(.105)^{*}$ & $* \quad-.957(.158) * *$ & $-.484(.177)^{* * *}$ & $-1.298(.208) * *$ \\
\hline \multicolumn{6}{|l|}{$\begin{array}{l}\text { Control } \\
\text { Variables }\end{array}$} \\
\hline $\begin{array}{l}\text { Gender } \\
(0=\text { Male })\end{array}$ & & & & $-1.022(.176)^{* *}$ & $-.851(.182)^{* *}$ \\
\hline \multicolumn{6}{|l|}{$\begin{array}{l}\text { Race } \\
(0=\text { White })\end{array}$} \\
\hline Black & & $-.311(.213)$ & $-.339(.215)$ & $-.280(.221)$ & $-.313(.225)$ \\
\hline Hispanic & & $-.488(.304)$ & $-.493(.307)$ & $-.517(.312)$ & $-.483(.317)$ \\
\hline Asian & & $-.266(.436)$ & $-.288(.438)$ & $-.478(.447)$ & $-.518(.460)$ \\
\hline American & & $-.046(.359)$ & $-.033(.360)$ & $-.122(.366)$ & $-.169(.381)$ \\
\hline \multicolumn{6}{|l|}{ Indian } \\
\hline \multicolumn{6}{|c|}{$\begin{array}{l}\text { Education } \\
(0=\text { High School Diploma })\end{array}$} \\
\hline Drop out & & & $.044(.255)^{*}$ & $.015(.265)^{*}$ & $.111(.271)^{*}$ \\
\hline GED Received & & & $-.354(.360)$ & $-.396(.367)$ & $-.469(.382)$ \\
\hline $\begin{array}{l}\text { Enrolled in } \\
\text { School }\end{array}$ & & & $-.084(.185)$ & $-.008(.190)$ & $.015(.194)$ \\
\hline $\begin{array}{l}\text { College Degree } \\
\text { Earned }\end{array}$ & & & $-.918(.623)$ & $-.903(.632)$ & $-.900(.643)$ \\
\hline $\begin{array}{l}\text { Ever } \\
\text { Arrested }\end{array}$ & & & & & $1.411(.298)^{* *}$ \\
\hline \multicolumn{6}{|l|}{ Cohabitation } \\
\hline \multicolumn{6}{|l|}{$\begin{array}{l}\text { Independent } \\
\text { Variables } \\
(0=\mathrm{No})\end{array}$} \\
\hline \multirow{2}{*}{$\begin{array}{l}\text { MA } \\
\text { Use }\end{array}$} & $1.812(.477)^{* *}$ & $1.776(.484)^{* *}$ & $1.798(.489) * *$ & $1.894(.505)^{* *}$ & $1.745(.517)^{* *}$ \\
\hline & $\begin{array}{r}\text { Source: } \mathrm{Na} \\
\text { Note: }\end{array}$ & $\begin{array}{l}\text { tional Longitudin } \\
\text { Standard errors in }\end{array}$ & $\begin{array}{l}\text { al Survey on Ad } \\
\text { parentheses. }{ }^{*} \text { p }\end{array}$ & $\begin{array}{l}\text { olescent Health } 2008 \\
<0.05 . * * \mathrm{p}<0.01\end{array}$ & \\
\hline
\end{tabular}




\begin{tabular}{|c|c|c|c|c|}
\hline & Model 6 & Model 7 & Model 8 & Model 9 \\
\hline & $\mathbf{B} / \mathbf{S E}$ & $\mathbf{B} / \mathbf{S E}$ & $\mathbf{B} / \mathbf{S E}$ & $\mathbf{B} / \mathbf{S E}$ \\
\hline Constant & $-.720(.187)^{* *}$ & $-.819(.191)^{* *}$ & $-1.332(217)^{* * *}$ & $-1.810(.242)^{* * *}$ \\
\hline \multicolumn{5}{|l|}{$\begin{array}{l}\text { Control } \\
\text { Variables }\end{array}$} \\
\hline $\begin{array}{l}\text { Gender } \\
(0=\text { Male })\end{array}$ & $-.834(.183)^{* *}$ & $-.852(.186)^{* *}$ & $-.799(.193)^{* *}$ & $-.958(.218)^{* *}$ \\
\hline \multicolumn{5}{|l|}{$\begin{array}{l}\text { Race } \\
(0=\text { White })\end{array}$} \\
\hline Black & $-.339(.226)$ & $-.256(.243)$ & $-.152(.240)$ & $.529 \quad(.248)$ \\
\hline Hispanic & $-.467(.318)$ & $-.443(.321)$ & $-.238(.327)$ & $.161 \quad(.340)$ \\
\hline Asian & $-.483(.461)$ & $-.427(.460)$ & $-.264(.478)$ & $-.692 \quad(.651)$ \\
\hline $\begin{array}{l}\text { American } \\
\text { Indian }\end{array}$ & $-.183(.383)$ & $-.035(.384)$ & $-.021(.401)$ & $-.168 \quad(.433)$ \\
\hline \multicolumn{5}{|c|}{$\begin{array}{l}\text { Education } \\
(0=\text { High School Diploma })\end{array}$} \\
\hline Drop out & $.124(.275)^{*}$ & $.157(.279)^{*}$ & $.280(.288)^{*}$ & $.601(283)^{*}$ \\
\hline GED Received & $-.430(.272)$ & $-.480(.390)$ & $-.298(.400)$ & $-.310(.413)$ \\
\hline Enrolled in School & $-.002(.194)$ & $-.006(.197)$ & $-.123(.206)$ & $-.330(.235)$ \\
\hline $\begin{array}{l}\text { College Degree } \\
\text { Earned }\end{array}$ & $-.931(.645)$ & $-.826(.644)$ & $-.629(.672)$ & $.338(1.190)$ \\
\hline $\begin{array}{l}\text { Ever } \\
\text { Arrested }\end{array}$ & $1.432(.299)^{* *}$ & $1.348(.305)^{* *}$ & $1.153(.319)^{* *}$ & $1.147(.309)^{* *}$ \\
\hline Cohabitation & $.672(.370)$ & $.629(.376)$ & $-.573(.381)$ & $-.131 \quad(.480)$ \\
\hline \multicolumn{5}{|l|}{$\begin{array}{l}\text { Independent } \\
\text { Variables } \\
(0=\mathrm{No})\end{array}$} \\
\hline MA Use & $1.742(.518)^{*}$ & $.520(.657)$ & $.211(.599)$ & $.577(.122)$ \\
\hline $\begin{array}{l}\text { Cocaine } \\
\text { Use }\end{array}$ & & $1.703(.385)^{* *}$ & $1.084(.397)^{*}$ & $1.173(.418)^{*}$ \\
\hline Marijuana & & & $1.364(.197) * *$ & $.915(.225)^{* *}$ \\
\hline \multicolumn{5}{|l|}{ Use } \\
\hline Coc/MA Use & & & & $1.062(.408)$ \\
\hline
\end{tabular}


Using the National Longitudinal Survey on Adolescent Health 2008, a logistic regression was performed to analyze the association between methamphetamine use in the past 12 months, cocaine use in the past 12 months, marijuana use in the past 12 months and violent crime committed within the past 12 months. The results of these analyses are reported in Table 8. In model 1, the coefficient for methamphetamine use in the past 12 months is positive and significant ( $\mathrm{p}=.011)$. The odds ratio for methamphetamine users in the past 12 months versus non-methamphetamine users is exp $(1.812)=6.123$. This implies that the odds of committing a violent crime within the past 12 months is 6.123 times as likely for methamphetamine users as it is for nonmethamphetamine users. Methamphetamine use within the past 12 months increases the likelihood of committing a violent crime within the past 12 months in comparison to those who did not use methamphetamine within the past 12 months.

In model 2, race, which includes Black, Hispanic, Asian, American Indian and White as the reference category, was added to the model. The coefficient for methamphetamine use in the past 12 months remains positive and significant $(\mathrm{p}=.010)$. This implies that the odds of committing a violent crime within the past 12 months is 5.906 times as likely for methamphetamine users as it is for non-methamphetamine users. The coefficient for race is non-significant.

In model 3, education, which includes high school drop-out, currently enrolled in school, GED received, 4 year bachelor's degree or higher received and high school diploma received as the reference category is controlled for. The coefficient for high school drop-out is positive and significant $(\mathrm{p}=.012)$. This implies that the odds of 
committing a violent crime within the past 12 months is 1.045 times as likely for high school drop outs as it is for those respondents who obtained a high school diploma. The coefficient for methamphetamine use in the past 12 months is positive and significant $(\mathrm{p}=.011)$. This implies that the odds of committing a violent crime within the past 12 months is 6.038 times as likely for methamphetamine users as it is for nonmethamphetamine users.

In model 4, gender is added, the reference category is male. The coefficient for gender is also significant $(\mathrm{p}=.000)$. This implies that the odds of committing a violent crime within the past 12 months is 1.779 times as likely for male respondents as it is for female respondents. The coefficient for methamphetamine use within the past 12 months is positive and significant ( $\mathrm{p}=.012)$. The coefficient for methamphetamine use drops from 1.894 to 1745 with the addition of the coefficient ever arrested (in one's lifetime). This implies that the odds of committing a violent crime within the past 12 months is 5.726 times as likely for methamphetamine users as it is for non-methamphetamine users. The coefficient for high-school drop-out remains significant at $(\mathrm{p}=.006)$.

In model 5, previously arrested in added to the model. The coefficient of ever arrested (in one's lifetime) is positive and statistically significant $(\mathrm{p}=.000)$. This implies that the odds of committing a violent crime within the past 12 months is 4.100 times as likely for respondents who have been arrested in their lifetime as it is from respondents who have not been arrested sometime in their lifetime. The coefficient for methamphetamine use rises from 1.798 to 1.894 and still positive and significant $(\mathrm{p}=.012)$. This implies that the odds of committing a violent crime within the past 12 months is 6.645 times as likely for methamphetamine users as it is for non- 
methamphetamine users. The coefficient for high-school drop-out also remains significant at $(\mathrm{p}=.006)$. The coefficient for high school drop-out remains positive and significant $(\mathrm{p}=.021)$. This implies that the odds of committing a violent crime within the past 12 months is 1.117 times as likely for high school drop outs as it is for respondents who have obtained a high school diploma. The coefficient for gender also remains significant $(\mathrm{p}=.000)$.

In model 6, cohabitation is added (1=Does not cohabit, lives alone). Methamphetamine use within the past 12 months remains significant $(\mathrm{p}=.050)$. The coefficient of ever arrested (in one's lifetime) remains positive and statistically significant $(\mathrm{p}=.000)$. The coefficient for high school drop-out remains significant $(\mathrm{p}=.021)$. The coefficient for gender is also not effected and remains significant $(\mathrm{p}=.000)$.

In model 7, cocaine use within the past 12 months is added. The coefficient for cocaine use within the past twelve months is positive and significant $(\mathrm{p}=.000)$. This implies that the odds of committing a violent crime within the past 12 months is 5.490 times as likely for respondents who have used cocaine within the past 12 months as it is for respondents who have not used cocaine within the past 12 months. Methamphetamine use within the past 12 months becomes non-significant with the addition of cocaine use. The coefficient of ever arrested (in one's lifetime) remains positive and statistically significant $(\mathrm{p}=.000)$. The coefficient for high school drop-out rises with the addition of cocaine use and remains significant $(\mathrm{p}=.030)$. This implies that the odds of committing a violent crime within the past 12 months is 1.170 times as likely for high school drop outs 
as it is for respondents who have obtained a high school diploma. The coefficient for gender remains significant $(\mathrm{p}=.000)$.

In model 8, marijuana use within the past 12 months is added. The coefficient for marijuana use within the past twelve months is positive and significant $(\mathrm{p}=.000)$. This implies that the odds of committing a violent crime within the past 12 months is 3.912 times as likely for respondents who have used marijuana in the past 12 months as it is for respondents who have not used marijuana. Methamphetamine use within the past 12 months remains non-significant. The coefficient for cocaine use is affected by the addition of marijuana use within the past 12 months to the model. The coefficient drops from 1.703 to 1.084 . The coefficient remains positive and significant ( $\mathrm{p}=.008)$. This implies that the odds of committing a violent crime within the past 12 months is 2.956 times as likely for respondents who used cocaine within the past 12 months as it is for respondents who have not used cocaine within the past 12 months. The coefficient for high school drop-out is also affected by the addition of marijuana use within the past 12 months to the model. The coefficient for high school drop-out rises from .157 to .280. This implies that the odds of committing a violent crime within the past 12 months is 1.323 times as likely for high school drop outs as it is for respondents who have obtained a high school diploma. High school drop- out remains significant $(\mathrm{p}=.049)$. The coefficient of ever arrested (in one's lifetime) remains positive and statistically significant $(\mathrm{p}=.000)$. The coefficient of ever arrested decreases from 1.348 to 1.153 when marijuana use within the past 12 months if added to the model. This implies that the odds of committing a violent crime within the past 12 months is 3.168 times as likely for 
respondents who have been previously arrested as it is for respondents who not been arrested in their lifetime. The coefficient for gender remains significant $(\mathrm{p}=.000)$.

In model 9, the interaction of methamphetamine use and cocaine use within the past 12 months is added to the model. The coefficient is non-significant. The coefficient for marijuana use drops significantly from 1.364 to .915 but remains positive and significant $(\mathrm{p}=.000)$. This implies that the odds of committing a violent crime within the past 12 months is 2.497 times as likely for respondents who have used marijuana in the past 12 months as it is for respondents who have not used marijuana. The coefficient for cocaine use rises from 1.084 to 1.173 and remains positive and significant $(\mathrm{p}=005)$. This implies that the odds of committing a violent crime within the past 12 months is 3.232 times as likely for respondents who used cocaine within the past 12 months as it is for respondents who have not used cocaine within the past 12 months. The coefficient of ever arrested (in one's lifetime) remains positive and statistically significant $(\mathrm{p}=.000)$. The coefficient rises dramatically from 1.153 to 1.470 with the addition of methamphetamine and cocaine use. This implies that the odds of committing a violent crime within the past 12 months is 4.349 times as likely for respondents who have been previously arrested as it is for respondents who not been arrested in their lifetime. The coefficient for gender remains negative and significant $(\mathrm{p}=.000)$. The coefficient for high school drop-out rises from .280 to .601 with this addition. This implies that the odds of committing a violent crime within the past 12 months is 1.824 times as likely for high school drop outs as it is for respondents who have obtained a high school diploma. High school drop- out remains significant $(\mathrm{p}=.034)$. Methamphetamine use is still nonsignificant. 


\section{Chapter 6. Discussion}

\section{Drug Sales}

According to previous research, the crime of selling drugs is the most principal criminal activity among drug users (Harrison \& Gfroerer, 1992). Methamphetamine usage (before controlling for cocaine use) and the positive and significant association with drug sale crime is supported by previous literature. Gizz and Gerkin (2009), show that regular meth users were most likely to have their charges involve drug offenses. Drug possession and distribution charges represented $48.9 \%$ of all responses. Of the 43 drug charge responses, $28(65.2 \%)$ were possession charges.

However, once cocaine use was controlled for methamphetamine use became non-significant. These results are based off a low frequency of methamphetamine users which could account for the lack of statistical power associated with methamphetamine use. However it is more likely that this result shows it is not the methamphetamine use that is associated with selling drugs but the cocaine use. Therefore, once cocaine use is controlled for methamphetamine use is not associated with selling drugs in comparison to non-users. This result does not support the hypothesis.

Cocaine use and its association to drug sale crimes is also supported by previous literature. Collins et al. (1985) found that frequency of cocaine use was strongly associated with the commission of income-generating crime.

Previous studies also show that marijuana is associated with the sale of the drug, which is a non-violent crime (Wish \& Johnson, 1986). Therefore, the positive and 
significant association between drug use overall and crime can be explained by the systematic model of crime (Goldstein, 1985). Those who use drugs are more likely than those who do not use drugs to become involved in the illegal drug market. According to Goldstein (1985), the systematic model suggests that those involved with the illegal drug market, such as distributing or manufacturing illegal drugs have an increased association with crime.

Gender was also significantly associated with drug sale crimes. Males overall were more likely than females to commit drug sale crimes. Gender, which was added in model 4, was significant and remained significant throughout the logistic regression. This finding is consistent with previous literature, which states that males are more likely than females to commit crimes (Pennell, 1999; Hendelang, Hirschi \& Weiss, 1981).

Previously arrested was also statistically significant and remained significant through -out the logistic regression. Overall, respondents who had been arrested sometime in their life had an increased risk of selling drugs than respondents who had never been arrested. This finding is consistent with previous research. Previous literature states, once an individual has experience with the criminal justice system they are more likely to commit another crime in comparison to those who have never been arrested (Freeman, 2003).

\section{Property Crime}

Methamphetamine use within the past 12 months was shown to be associated with an increased likelihood of committing property crimes but only until cocaine use was 
controlled for. This does not support the hypothesis, which states that methamphetamine use reported in the last 12 months will not be associated with committing a property crime within the past 12 months. However, this finding is supported by certain previous studies. Previous research studies support the association between methamphetamine use and an increased likelihood of committing a property crime. Gizzi and Gerkin (2009), show that when meth users were arrested the second largest category of responses as to what their arrest was for was property crimes. Also, Goldstein (1985) defines economiccompulsive violence as the efforts drug users use to obtain money to finance the high costs of illicit drugs. This could be robbery, burglary or larceny in which the money is used to finance the drug habit.

Also, this result may provide evidence toward the similarities made by the media and certain studies regarding the effects methamphetamine and cocaine of on their user. Literature suggests a similarity between cocaine and methamphetamine and the effects that each drug has on its users (Glasner-Edwards 2008, Garlow et al. 2002). Therefore, if cocaine use is associated with an increased likelihood of committing property crime (McGlothlin, 1978; Collins et al., 1985; Anglin \& Speckart, 1988) then, according to the research stated above, methamphetamine use may also be associated with property crime.

Once cocaine use was controlled for, the association between methamphetamine use and property crime became non-significant. When marijuana was added the methamphetamine use was still non-significant, while cocaine use and marijuana use were both significant. This finding does support the hypothesis and is supported by previous research (Wermuth, 2000; Boles \& Miotto, 2003; Sommers \& Baskin 2006). 
This result suggests that is not methamphetamine that is associated with property crime but cocaine (and marijuana).

In the case of methamphetamine, economic-compulsive crime is less likely than for other drugs. For example, some drug habits such as cocaine and heroin are expensive and so economic violence is more likely to be related to these particular drugs (Boles \& Miotto, 2003). Additionally, methamphetamine is more likely than other drugs such as cocaine to be made for consumption purposes by small-time entrepreneurs (Wermuth, 2000). Therefore, methamphetamine users are likely to be purchasing cheaper drugs and are purchasing their drug of choice from a small time entrepreneur instead of a gang, cartel or larger scale drug trafficking organization which does not support the suggested link between methamphetamine and economic-compulsive crime.

Cocaine use was statistically significant when added to the logistic regression. This finding supported the hypothesis and was supported by previous literature. Previous research shows that narcotic addicts greatly increase their level of criminal offending during periods of elevated narcotic use (Anglin \& Speckart, 1988). McGlothlin (1978) has shown that income from property crime escalates with increasing narcotic use.

The interaction of cocaine and methamphetamine use was added to logistic regression 9 in table 7 which affected the coefficient for cocaine use. The coefficient for cocaine use dropped once the interaction of cocaine and methamphetamine use was added to the regression. It is stated earlier that the majority of respondents who admitted to methamphetamine use within the past 12 months also admitted to cocaine use in the 
past 12 months but the majority of respondents who admitted to cocaine use within the past 12 months did not admit to methamphetamine use within the past 12 months. Therefore, since the coefficient for cocaine use dropped once the interaction of cocaine and methamphetamine was added this could further support methamphetamine use may play a more pivotal role in the commitment of property crimes but likely through its relationship with cocaine.

Marijuana use within the past 12 months was positively and significantly associated with an increased likelihood of committing a property crime within the past 12 months. This finding does not support the stated hypothesis and contradicts previous research and literature. Harrison \& Gfroerer, (1992) state, there is virtually no research indicating an association between marijuana use and crime for economic gain. This positive association between marijuana use and property crime could again also explained by the poly-drug users; those who use harder drugs and marijuana simultaneously and therefore, it is not the marijuana use that provides the association with property crime but the harder drug being used.

Gender was also significantly associated with drug sale crimes. Males overall were more likely than females to commit drug sale crimes. Gender, which was added in model 4 was significant and remained significant throughout the logistic regression. This finding is consistent with previous literature, which states that males are more likely than females to commit crimes (Pennell, 1999; Hendelang, Hirschi, and Weiss, 1981). 
Previously arrested was also statistically significant and remained significant through- out the logistic regression. Overall, respondents who had been arrested sometime in their life had an increased risk of selling drugs than respondents who had never been arrested. This finding is consistent with previous research. Previous literature states, once an individual has experience with the criminal justice system they are more likely to commit another crime in comparison to those who have never been arrested (Freeman, 2003).

\section{Violent Crime}

Methamphetamine use within the past 12 months was associated with an increased likelihood of committing a violent crime within the past 12 months in comparison to non-methamphetamine users, until cocaine use was controlled for. This finding supports the hypothesis which suggested a positive and significant relationship between methamphetamine use and violent crime.

First, this study found that methamphetamine use within the past 12 months was associated with an increased likelihood of committing a violent crime within the past 12 months, controlling for race, education, cohabitation, previous arrest and gender only. This research supports the hypothesis that methamphetamine use is associated with an increased likelihood of committing a violent crime. Also, this finding supports previous research (Pihl \& Hoaken, 1997, Reiss \& Roth 1993; Dillon, Fritz, Blanton et al. 2000; Cartier, Farabee \& Prendergast 2005; Sommers \& Baskin, 2006; Cartier et al., 2006) which demonstrated methamphetamine use as a significant predictor of violent acts. 
This finding also supports the suggested notion that cocaine and methamphetamine share a similar chemical make- up and therefore may in fact produce similar effects (Glasner-Edwards 2008, Garlow et al. 2002). Previous research on cocaine has received more attention from researchers than any other illegal drug. Researchers have shown an association between cocaine use and an increased likelihood of committing a violent act (Glasner-Edwards, 2008; Garlow et al. 2002). Researchers have also documented similar effects of cocaine and methamphetamine on a user (Glasner-Edwards 2008, Garlow et al. 2002). Research suggests that cocaine and methamphetamine have similar but not identical mechanisms of action and share common psychiatric and psychosocial consequences (Glasner- Edwards et al., 2008). This study found an association between methamphetamine use and violent crime and an association between cocaine use and violent crime which may suggest that the effects of cocaine and methamphetamine on a user may be more similar than initially suggested. This study supports this comparison between cocaine and methamphetamine.

Once cocaine use was controlled for, methamphetamine use became nonsignificant. This finding could be the result of the small sample of methamphetamine users in comparison to the larger sample of cocaine users and even larger sample of marijuana users used in this study. However, it is more probable that this result suggests that it is not the methamphetamine use that is associated with the commitment of a violent crime but the cocaine use that has the significant association with violent criminal acts. When cocaine use is controlled for, methamphetamine use became non-significant. This finding could suggest that cocaine use is a significant predictor of violent criminal 
acts and methamphetamine use is not. This finding is supported by previous research (Iritani \& Hallfors \&Bauer, 2007; Gizzi \& Gerkin, 2009), which did not find a significant association between methamphetamine use and violence.

Cocaine use within the past 12 months was shown to be associated with an increased likelihood of committing a violent crime. This finding supports the hypothesis and is supported by previous literature (Johnson Wish \& Huizinga, 1993). Cocaine use and its positive and significant association with violent crime can be explained using Goldstein's drug crime nexus. The systematic model suggests that those involved with the illegal drug market, such as distributing or manufacturing illegal drugs have an increased association with crime and violence. Sommers and Baskin (2006), describe cocaine and especially crack distribution as being entrenched in [violent] street networks" (p. 87). Therefore, the violent crime associated with cocaine use may be caused by the gang life responsible for the distribution of cocaine in the United States.

Additionally, the violent crime associated with cocaine use found in this study could be explained by Goldstein's (1985) economic-compulsive model. The economiccompulsive model is defined as the efforts drug users use to obtain money to finance the high costs of illicit drugs. This could be robbery, burglary or larceny in which the money is used to finance the drug habit. Violent criminal activity could occur if the individual uses physical force or the threat of physical force in order to obtain finances to support their drug habit. Some drug habits such as cocaine and heroin are expensive and so economic violence is more likely to be related to these particular drugs (Boles \& Miotto, 2003). Cocaine because of its addictive potential and high cost could lead users to 
commit violent crimes in order to obtain money to fund their drug habit which could explain the association between cocaine use and violent crime found in this study.

When the interaction of cocaine and methamphetamine was added to model 9 in table 8 , the coefficient for cocaine use was positively affected. It is stated earlier that the majority of respondents who admitted to methamphetamine use within the past 12 months also admitted to cocaine use in the past 12 months but the majority of respondents who admitted to cocaine use within the past 12 months did not admit to methamphetamine use within the past 12 months. Therefore, since the coefficient for cocaine use rose once the interaction of cocaine and methamphetamine was added this could further support that it may be the cocaine use that has more a significant association with violent crime in comparison to methamphetamine.

Marijuana use within the past 12 months was positively and significantly associated with committing a violent crime within the past 12 months. This finding does not supports the hypothesis stated and contradicts previous research and literature which found no association between marijuana use and violence (Gandossy et al., 1980; Wish \& Johnson, 1986). This finding could be explained by the fact that marijuana is the most frequently and commonly used drug according to the 2011 National Survey on Drug Use and Health. Therefore, this finding may suggest that those individuals who are using harder drugs such as cocaine are also using marijuana. Marijuana users are frequently multiple drug users, however, it is difficult to isolate the criminogenic effects of any one substance (Wish \& Johnson, 1986). Therefore, the association found between marijuana use and an increased likelihood of committing a violent crime could be attributed to 
harder drug users (ie. Methamphetamine and cocaine users), who are also using marijuana.

High school drop-out, in reference to obtaining a high school diploma, was significant when added to the violent crime logistic model 3 and remained significant throughout. This finding supports previous literature which states that education is negatively associated with drug use and crime. In essence, the more education a person receives the less likely they are to commit crimes or use drugs (Lochner \& Moretti 2004). Therefore, if an individual has dropped out of high school in comparison to obtaining a high school diploma there is a higher probability of committing a violent crime.

Gender was also significantly associated with drug sale crimes. Males overall were more likely than females to commit drug sale crimes. Gender, which was added in model 4 was significant and remained significant throughout the logistic regression. This finding is consistent with previous literature, which states that males are more likely than females to commit crimes (Pennell, 1999; Hendelang, Hirschi, and Weiss, 1981).

Previously arrested was also statistically significant and remained significant through- out the logistic regression. Overall, respondents who had been arrested sometime in their life had an increased risk of selling drugs than respondents who had never been arrested. This finding is consistent with previous research. Previous literature states, once an individual has experience with the criminal justice system they are more likely to commit another crime in comparison to those who have never been arrested (Freeman, 2003). 


\section{$\underline{\text { Limitations }}$}

One limitation of this study is that there is no definitive way to show if the illegal drug use occurred before the committed crime. Even though both illegal drug usage and crime committed are measured in past 12 months, drug usage still could have occurred after the crime committed. Secondly, the frequency use rates for methamphetamine were much smaller in comparison to cocaine and marijuana usage. Therefore, the results could have been affected and methamphetamine use could have more of an effect than shown in this study. However, the demographics of methamphetamine users is quite similar to that of cocaine users and marijuana users. Thirdly, age was not used as a control variable. Age was not used as a control variable because the survey was already limited to young adults, aged 18-26 with the majority of respondents falling between 22 and 24 years of age. Therefore, since the majority of respondents are aged between 22 and 24 it is likely that the drug crime nexus and its effects can be interpreted the same for this sample.. Lastly, the data set used was from 2008, which could mean that the results are not generalizable to young adults today.

\section{Further Research}

Further research must be done on methamphetamine use and the effects of using this drug. Research studies should be done particularly on why individuals start using methamphetamine and what actions occur once they are on the drug. Methamphetamine use and the crimes that people commit while under the influence of the drug is especially important. Media coverage has suggested that while under the influence of 
methamphetamine violence ensues. It is essential to study whether or not violent acts are committed not simply by methamphetamine users but rather while a methamphetamine user is under the influence of the drug. It is imperative to research the impact that methamphetamine has on its user and on society as a whole.

Additionally, the cocaine/methamphetamine paradigm should be explored in further research. Research should be done comparing the initiation into cocaine use and methamphetamine use. Then comparing the effects the drug has on the user. Is the crimes cocaine users commit different and motivated differently than the crimes methamphetamine users commit? 


\section{Chapter 7. Conclusion}

In conclusion, this thesis aimed to provide evidence to the research questions, does the illegal drug use defined as (methamphetamine, cocaine and marijuana use within the past 12 months) increase the risk of committing crime, (defined as drug sales, violent and property crime within the past 12 months). This thesis found that once cocaine use was controlled for, methamphetamine use was not associated with an increased risk of committing any crime. This result suggests that it is not methamphetamine that has the association with crime but cocaine.

The comparisons made by the media, politicians and previous studies regarding the similar effects that cocaine and methamphetamine have on their users are not supported by this study. In fact, this study provides evidence that methamphetamine use unlike cocaine use is not associated with an increased risk of committing any crime.

Goldstein's (1985), drug-crime nexus provides a theoretical explanation as to why certain drugs are associated with crime. Firstly, cocaine was shown to be associated with an increased risk of committing crime. The mere act of ingesting cocaine is not shown to be associated with any criminal activity; however, using cocaine does put an individual at an increased risk of committing a drug sale crime, property crime or violent crime because of the manufacturing and distribution of drugs by the cartel or gangs. Crime could also occur because using a drug as expensive as cocaine could result in a need to steal in order to fund the drug habit. These two scenarios could also result in a violent crime being committed as well. 
Methamphetamine however, which was not associated with crime is low in cost to manufacture and low in cost to purchase. Methamphetamine is cheaper than cocaine and crack cocaine for that matter according to the Institute for Defense Analysis (2008), Estimated the Annual Price per Expected Pure Gram of Methamphetamine in various Cities, Retail Level (0.1 - 1.0 g, Evaluated at $0.3 \mathrm{~g})$, Constant 2007 Dollars ranges from $\$ 16.10$ to $\$ 139.13$ depending on the purity level. In comparison, the street price of cocaine ranges from $\$ 51.62$ to $\$ 304.66$ depending on the purity level. The street price of crack cocaine ranges from $\$ 61.23 \$ 318.20$ depending on the purity level. This coupled with the fact that it is manufactured by small time entrepreneurs in comparison to cocaine which is handled by cartels and gangs could provide an explanation for the lack of association between methamphetamine use and crime.

Sensationalizing drug effects and casting fear on society failed to bring the use of crack down or lessen the effects that this drug had on society as a whole. Therefore, it is essential that we learn from this mistake and begin to take a closer look at methamphetamine and the way in which it interacts with our society. This study provides evidence that methamphetamine itself is not associated with an increased risk of committing crime. Instead of using the criminal justice system to lock away drug users for mandatory minimum sentences, especially when there are studies providing evidence that methamphetamine use alone is not associated with crime, different options should be considered to treat this drug using population.

When fear began to rise with the crack cocaine epidemic, prison instead of treatment was used as a solution to prevent and treat drug use and its effects. However, 
this only lead to an exceedingly alarming amount of people (specifically, low income and minority individuals) housed in our prison system for drug offenses. This study shows that cocaine use is associated with an increased rate of committing crime. Therefore, since people are still using cocaine and cocaine use is still associated with crime what did imprisoning crack/cocaine users achieve besides adding to a prison population that was already out of control? From the crack/cocaine epidemic, society can learn that imprisonment does not prevent or deter drug use and crime. This study found that methamphetamine use alone is not associated with crime. Therefore, the act of simply using a drug should not result in a prison system but in treatment. Our society cannot afford to imprison another drug using population, especially when imprisonment usually results in the offender coming out worse than when they went in. Imprisonment did not deter or prevent cocaine use or crime associated with cocaine use, therefore it is time our society learned from previous mistakes and opted for a more beneficial plan to treat drug use, treatment instead of prison. 


\section{$\underline{\text { References }}$}

Albertson, T., Walby, W., \& Derlet, H. (1995). Stimulant-induced pulmonary toxicity. Chest Journal, 108, 1140-1149.

Angeli, D. H. (1996). Second Look at Crack Cocaine Sentencing Policies: One More Try for Federal Equal Protection, A. Am. Crim. L. Rev., 34, 1211.

Anglin, M., \& Speckhart, G. (1988). Narcotics use and crime: a multisample, multimethod analysis. Crimonology, 26, 197-233.

Anglin, M., \& Rawson, R. (2002). Treatment of methamphetamine use disorders: an Journal of Psychoactive Drugs, 32(2), 135-136.

Beebe, D. K., \& Walley, E. (1995). Smokable methamphetamine ('ice'): an old drug in a different form. American Family Physician, 51(2), 449.

Blumstein, A. (1995). Youth violence, guns, the illicit drug industry. J. Crim. Law Criminal. , 86(1), 10-36.

Boles, S., \& Miotto, K. (2003). Substance abuse and violence: A review of the literature.Aggression and Violent Behavior, 8, 155-174.

Brecht, M. (2001). Update on methamphetamine use trends in California. UCLA Integrated Substance Abuse Program. 
Cartier, J., Farabee, D., \& Prendergast, M. L. (2006). Methamphetamine use, selfreported violent crime, and recidivism among offenders in California who abuse substances. Journal of interpersonal violence, 21(4), 435-445.

Chitwood, D. D., Murphy, S., \& Rosenbaum, M. (2009). Reflections on the meaning of drug epidemics. Journal of Drug Issues, 39(1), 29-39.

Collins, J., \& Allison, M. (1983). Legal coercion and retention in drug abuse treatment. . Hosp Community Psychiatry, 34(12), 1145-1149.

Dillion, H., Fritz, L., Blanton, L., Thorne, B., \& Marshall, R. (2000). A look at methamphetamine use among three populations. U.S. Department of Health and Human Services.

Dillon, J. (2006). Meth epidemic forcing grandparents to raise grandchildren. The Associated Press State \& Local Wire.

Farrington, D. P. (1986). Age and crime. Crime and justice, 189-250.

Fischman, M., \& Haney, M. (1999). Neurobiology of stimulants. In Textbook of ‘ substance abuse treatment (2 ed., pp. 21-31). Washington, DC: American Psychiatric Press.

Freeman, R. B. (2003). Can we close the revolving door?: Recidivism vs. employment of ex-offenders in the US. 
Fries, A., Anthony, R. W., Cseko Jr, A., Gaither, C. C., \& Schulman, E. (2008). The price and purity of illicit drugs: 1981-2007 (No. IDA-P-4369). Institute for Defense Analysis.

Gandossy, R., Williams, J., Cohen, J., \& Harwood, H. (1980). A Survey and Analysis of the Literature. U.S. Department of Justice, National Institute of Justice, 173.

Garlow, S., \& Orio, B. (2002). Cocaine Use disorders and suicide ideation. Drug and Alcohol Dependence, 70(1), 101-104.

Gizzi, M., \& Gerkin, P. (2010). Methamphetamine Use and Criminal Behavior. ‘ International Journal of Offender Therapy and Comparative Criminology, 54, 915-916.

Glasner-Edwards, S., Mooney, L., Marinelli-Casey, P., \& Hillhouse, M. (2008). Risk factors for suicide attempts in methamphetamine-dependent patients. The American Journal on Addictions, 17, 24-27.

Gleghorn, A., Marx, R., Vittinghoff, E., \& Katz, M. (1998). Association between drug use patterns and HIV risks among homeless, runaway, and street youth in northern California. Drug and Alcohol Dependence, 3, 219-227.

Harrison, L., \& Gfroerer, J. (1992). The intersection of drug use and criminal behavior: Results from the national household survey on drug abuse. Crime and Delinquency,38, 422-443. 
Hindelang, M. J., Hirschi, T., \& Weis, J. G. (1981). Measuring delinquency. Beverly Hills, CA: Sage Publications.

Irtani, B., Hallfors, D., \& Bauer, D. (2007). Crystal methamphetamine use among young adults in the USA. Addiction, 102, 1102-1113.

Johnson, B., Wish, E., \& Huzinga, D. (1993). Concentration of Delinquent Offending: Serious Drug Involvement and High Delinquency rates. Drugs and Crime , 1-25.

Katsumata, S., Sato, K., \& Kashiwade, H. (1993). Sudden death due presumably to internal use of methamphetamine. Forensic Science, 62(209-215), 1140-1149.

King, R. S. (2006). The Next Big Thing?: Methamphetamine in the United States. Sentencing Project.

Kosten, T., \& Singha, A. (1999). Stimulants. In Textbook of substance abuse treatment (2 ed., p. 183-193). Washington, DC: American Psychiatric Press.

Lattimore, P. (1997). Risk of Death Among Serious Young Offenders. Journal of Research in Crime and Delinquency, 34, 187-209.

Lochner, L. (2004). Education, work, and crime: A human capital approach. International Economic Review, 45(3), 811-843.

Lucas, S.E. 1997. Proceedings of the National Consensus Meeting on the Use, Abuse, and Sequelae of Abuse of Methamphetamine with Implications for Prevention, Treatment, and Research. Publication No. SMA 96-801 3. Rockville, Maryland: U.S. Department of Health and Human Services. 
Matza, D. (1964). Delinquency \& drift. Transaction Publishers.

McGlothlin, H. (1978). The etiologic relationship between drug use and criminality.Advances in Alcohol and Drug Problems, 4.

Meredith, C., Jaffe, C., Ang-Lee, K., \& Saxon, A. (2005). Implications of chronic methamphetamine use: A literature review. Harvard Review of Psychiatry, 13, $141-154$.

Morgan, P. (1997). Kinship and the community: The "ice" crisis in Hawaii. Harwood Academic Publishers Office of National Drug Control Policy.

National Institute on Drug Abuse. 1998b. MA Abuse and Addiction Research Report Series. Available online at http://www.nida.nih.gov.Goldstein, P. J. (1985). The drugs-violence nexus: A trispartite conceptual framework. Journal of Drug Issues, $15,493-506$.

Nauman, B. (2005) Attorney general calls meth an epidemic in Illinois. The Pantagraph, A3.

Nurco, D., Hanlon, T., Kinlock, T., \& Slaght, E. (1989). Final report: Drug offender typology development. National Institute of Justice.

Parker, R., \& Aerauhn, K. (1998). Alcohol, drugs and violence. Annual Review Sociology, 24, 291-31.

Pihl, R., \& Hoaken, P. (1997). Clinical correlates and predictors of violence in patients with substance use disorders. Psychiatric Annals, 27, 735-740. 
Pennell, S., Ellett, J., Rienick, C., \& Grimes, J. (1999). Meth matters: Report on ‘ methamphetamine users in Five Western states . National Institute of Justice, Office of Justice Programs.

Potter, M., \& Kolbye, K. (1996). Effects of d-MA. Washington. D.C.: National Drug Intelligence Center.

Rawson, R. A., Gonzales, R., \& Brethen, P. (2002). Treatment of methamphetamine use disorders: an update. Journal of substance abuse treatment, 23(2), 145-150.

Rawson, R., Gonzales, R., McCann, M., \& Obert, J. (2005). Methamphetamine use among treatment-seeking adolescents in Southern California: participant characteristics and treatment response. Juvenile Substance Abuse Treatment, 29, $67-74$.

Reinarman, C. (1994). The social construction of drug scares. Constructions of deviance: Social power, context, and interaction, 155-165.

Reiss, A., \& Roth, J. (1993). Understanding and preventing violence. National Academy Press, 182-220.

Ruff, J. (1997). Spread of meth near epidemic, Czar says. Lincoln Journal Star, 2.

Sampson, R. J., Laub, J. H., \& Wimer, C. (2006). Does Marriage reduce crime? A counterfactual approach to within-individual causes. Criminology, 44(3), 465508. 
Siegel, R. K. (1984). Changing patterns of cocaine use: longitudinal observations, consequences, and treatment. Cocaine: Pharmacology, effects, and treatment of abuse, 92.

Sommers, I. (2006). Methamphetamine use and violence. Journal of Drug Issues, 36, 77 95.

Substance Abuse and Mental Health Services Administration. 2008. National Survey on Drug Use and Health 2003.

Substance Abuse and Mental Health Services Administration. 2008. National Survey on Drug Use and Health 2005.

Substance Abuse and Mental Health Services Administration. 2008. National Survey on Drug Use and Health 2008.

Suwaki, H., \& Fukui, S. (1997). Methamphetamine abuse in Japan: Its 45 year history and the current situation. Amsterdam: Harwood Academic Publishers, 199-214.

Thompson, A. P., \& Putnins, A. L. (2003). Risk-need assessment inventories for juvenile offenders in Australia. Psychiatry, Psychology and Law, 10(2), 324-333.

Uggen, C., \& Thompson, M. (2003). The Socioeconomic Determinants of Ill-Gotten Gains: Within-Person Changes in Drug Use and Illegal Earnings1.American Journal of Sociology, 109(1), 146-185.

Waite, M. (1999). Methamphetamine sinks its teeth into Arkansas; like crack's epidemic rise in '80s, police say. Arkansas Democrat-Gazette. 1. 
Wermuth, L. (2000). Methamphetamine use: Hazards and social influences. Journal of Drug Education, 30, 423-433.

Wish, E., \& Johnson, B. (1986). The Impact of Substance Abuse on Criminal Careers and Criminal Careers. In A. Blumstein, J. Cohen, J. Rother, \& C. Visher (Eds.), (2 ed.). Washington, DC:National Academy Press.

Zernike, K. (2006, January 26). Potent Mexican meth floods in as states curb domestic variety. The New York Times. 